\title{
HFE gene variants, iron, and lipids: a novel connection in Alzheimer's disease
}

\author{
Fatima Ali-Rahmani ${ }^{1,2}$, Cara-Lynne Schengrund ${ }^{2}$ and James R. Connor ${ }^{1}$ * \\ 'Departments of Neurosurgery, Neural and Behavioral Sciences and Pediatrics, Center for Aging and Neurodegenerative Diseases, Penn State Hershey \\ Medical Center, Hershey, PA, USA \\ ${ }^{2}$ Departments of Biochemistry and Molecular Biology, The Pennsylvania State University College of Medicine, Hershey, PA, USA
}

\author{
Edited by: \\ Paolo Arosio, University of Brescia, \\ Italy \\ Reviewed by: \\ Torben Moos, Aalborg University, \\ Denmark \\ James Duce, University of Leeds, UK

\section{${ }^{*}$ Correspondence:} \\ James R. Connor, Departments of \\ Neurosurgery, Neural and Behavioral \\ Sciences and Pediatrics, Center for \\ Aging and Neurodegenerative \\ Diseases, Penn State Hershey \\ Medical Center, Hershey, PA 17033, \\ USA \\ e-mail: jconnor@hmc.psu.edu
}

Iron accumulation and associated oxidative stress in the brain have been consistently found in several neurodegenerative diseases. Multiple genetic studies have been undertaken to try to identify a cause of neurodegenerative diseases but direct connections have been rare. In the iron field, variants in the HFE gene that give rise to a protein involved in cellular iron regulation, are associated with iron accumulation in multiple organs including the brain. There is also substantial epidemiological, genetic, and molecular evidence of disruption of cholesterol homeostasis in several neurodegenerative diseases, in particular Alzheimer's disease (AD). Despite the efforts that have been made to identify factors that can trigger the pathological events associated with neurodegenerative diseases they remain mostly unknown. Because molecular phenotypes such as oxidative stress, synaptic failure, neuronal loss, and cognitive decline, characteristics associated with $A D$, have been shown to result from disruption of a number of pathways, one can easily argue that the phenotype seen may not arise from a linear sequence of events. Therefore, a multi-targeted approach is needed to understand a complex disorder like AD. This can be achieved only when knowledge about interactions between the different pathways and the potential influence of environmental factors on them becomes available. Toward this end, this review discusses what is known about the roles and interactions of iron and cholesterol in neurodegenerative diseases. It highlights the effects of gene variants of HFE (H63D- and C282Y-HFE) on iron and cholesterol metabolism and how they may contribute to understanding the etiology of complex neurodegenerative diseases.

\section{Keywords: iron, cholesterol, sphingolipids, Alzheimer disease, HFE, H63D, brain}

\section{INTRODUCTION}

The average increase in life expectancy has been accompanied by an increase in the number of people with dementia, a problem expected to affect half of those living to be 85 or older. The most prevalent form of dementia is Alzheimer's disease (AD) and its incidence is expected to triple by 2050 (Hebert et al., 2013). The observations that more than $40 \%$ of $\mathrm{AD}$ patients carried the ApoE4 allele (Cedazo-Minguez and Cowburn, 2001) and that those carrying both the ApoE4 allele and expressing the H63D variant of the hemochromatosis protein HFE were prone to earlier onset of AD (Moalem et al., 2000; Percy et al., 2008) support the hypothesis that disruption of the normal metabolism of both iron and cholesterol contribute to AD. More specifically, the need for a discussion of the role of iron and cholesterol in neurodegenerative disease stems from our observation that disruption of normal iron metabolism in H63D-HFE-expressing human neuroblastoma cells resulted in altered cholesterol metabolism as well as our findings that mice expressing the orthologous H67D-HFE had alterations in brain iron and cholesterol metabolism and a reduction in brain volume that correlated with poorer recognition and spatial memory, symptoms associated with AD (Ali-Rahmani et al., 2014a).

\section{IRON IN NEURODEGENERATIVE DISEASES}

Numerous studies have implicated metals such as iron, copper, zinc, and aluminum in the pathogenesis of $\mathrm{AD}$ (Sayre et al., 2000; Connor et al., 2001; Bush, 2003; Maynard et al., 2005; Connor and Lee, 2006; Liu et al., 2006; Roberts et al., 2012). Evidence indicates that oxidative stress induced by excess iron contributes to neurodegeneration (Castellani et al., 2007). Because iron is the most abundant transition metal in the body and is readily available from several dietary options, it is important to understand how its regulation in the body is influenced by other factors and how its elevation or depletion affects cellular processes that could lead to $\mathrm{AD}$ pathogenesis. To understand the role of iron in neurodegeneration, it is necessary to understand its normal function and regulation.

\section{ROLE OF IRON IN BRAIN}

Iron is essential for a number of cellular processes needed for survival. It is a required cofactor for a number of enzymes involved in cell functions such as energy production (mitochondrial electron transport chain), DNA synthesis and repair, ribosome biogenesis, neurotransmitter synthesis, myelin synthesis and lipid metabolism, and cell cycle regulation. Iron is also 
needed for heme production and formation of iron-sulfur clusters that are essential for electron transport and DNA repair (Rouault and Tong, 2005; Tong and Rouault, 2006). Though these reactions occur in every organ, the role of iron in the brain is particularly important. Brain has the highest demand for oxygen of all organs and iron-containing neuroglobin is essential to meet this need. In addition, to maintain the complex communication network and to establish plasticity, the brain constantly remodels cell contacts and synapses. These processes rely on protein synthesis by ribosomes which, in turn, depend on [4Fe-4S] cluster-containing proteins (Kispal et al., 2005). The iron-sulfur clusters are also essential for DNA synthesis (Netz et al., 2012). Moreover, iron is an essential trophic factor needed for myelination. This is because key enzymes such as 3-hydroxy-3-methylglutaryl-coenzyme A reductase (HMGCoAR), squalene synthase, and glucose-6-phosphate dehydrogenase needed for the biosynthesis of myelin cholesterol and lipids require iron as a cofactor (Lange and Que, 1998; Todorich and Connor, 2004). The role of iron in these processes is thought to reflect its ability to (1) donate electrons needed for redox reactions, (2) transfer electrons in mitochondria, and (3) to bind oxygen in heme. But if iron accumulates in an unchelated form, its ability to readily exchange electrons can result in formation of reactive free radicals by the Fenton reaction (Lloyd et al., 1997). In turn, this can lead to oxidative stress that can negatively impact a number of cellular processes and disrupt cell membrane integrity. Because oxidative stress is considered a causative agent in the etiology of AD (Castellani et al., 2007; Cai et al., 2011), the role of iron and disorders resulting in iron overload have been under intense investigation for their potential role as a risk factor for $\mathrm{AD}$.

\section{IRON IN AD}

Several studies have reported that brain iron content and expression of iron-regulating proteins such as ferritin (Frt; high expression indicates more iron) increase with age, but the increase in iron is greater than ferritin thus suggesting the increased iron is not stored properly (Hallgren and Sourander, 1958; Milton et al., 1991; Connor et al., 1992a,b, 1995; Bartzokis et al., 1994, 2007; Martin et al., 1998; Hirose et al., 2003). The finding that iron accumulation is significantly higher in brains of patients with $\mathrm{AD}$ or mild cognitive impairment (MCI) than in those of age-matched non-demented controls (Ding et al., 2009) supports the proposal that the increase in iron underlies age-related cognitive decline (Bartzokis, 2009). Disturbances in iron metabolism have been found in post-mortem brain tissue from patients with $\mathrm{AD}$, in cerebrospinal fluid (CSF) and in vivo using magnetic resonance imaging (MRI). Regions where iron deposition was found include the hippocampus, basal ganglia and cortex (Loeffler et al., 1995; Bartzokis et al., 2000; Ding et al., 2009) as well as senile plaques and neurofibrillary tangles and cells surrounding them (Connor et al., 1992a). Moreover, higher brain iron content was also found to correlate with the severity of cognitive impairment (Zhu et al., 2009). Thus, use of MRI to monitor brain iron has been proposed as a method for assessing disease progression. Excess unchelated iron is considered a major cause of oxidative stress that can lead to modification of proteins, lipids, DNA, and RNA, thereby, inducing several features associated with AD (Markesbery,
1997; Ferrari, 2000). These alterations are toxic to cells because they result in activation of cell apoptosis pathways and eventually cell death. In fact, markers of protein oxidation and lipid peroxidation were consistently found to be elevated in the brains and CSF samples from AD patients and those with MCI who subsequently developed AD (Markesbery, 1997; Pratico et al., 2002; Brys et al., 2009). Moreover, markers of lipid peroxidation in ventricular fluid were reported to correlate with cortical atrophy, reduced brain weight and severity of AD (Montine et al., 1999). Proteins involved in maintaining iron homeostasis include the transferrin receptor (TfR; iron uptake), transferrin (Tf; iron transport), ferritin (Frt; iron storage), HFE (iron uptake), ceruloplasmin (iron transport; feroxidase- conversion of $\mathrm{Fe}^{2+}$ to $\mathrm{Fe}^{3+}$ ), DMT1 (iron export), and ferroportin (iron export). Indeed, alterations in the expression pattern of Tf, Frt, and HFE were found in brains of AD patients and are discussed below. Moreover, genetic mutations in Tf (C2 variant; rs1049296) and two variants of HFE, C282Y (rs1800562) and H63D (rs1799945), were shown to affect body iron status (Fleming et al., 2000; Bartzokis et al., 2010; Kauwe et al., 2010), and oxidative stress (Loeffler et al., 1995; Lleo et al., 2002). Where $\mathrm{H} 63 \mathrm{D}$ has been associated with increased risk of $\mathrm{AD}, \mathrm{C} 282 \mathrm{Y}$ has been found to be protective for $\mathrm{AD}$. There is substantial evidence for the role of iron overload in $\mathrm{AD}$ that is further supported by epidemiological evidence implicating variants of iron management proteins in $\mathrm{AD}$ risk. The AlzGene meta-analysis of the Tf $\mathrm{C} 2$ allele (Bertram et al., 2007; www.alzgene.org/) currently shows a significant, although low, odds ratio of AD: 1.2 (95\% confidence interval, 1.06-1.3; June 2010), with a similar pattern in Caucasians and east Asians.

\section{IRON, HFE, AND AD}

Iron accumulation in the brain is accompanied by an increase in oxidative stress that is consistently observed in AD (Connor et al., 1992a; Markesbery, 1997; Liu et al., 2005; Maynard et al., 2005). The high iron (HFE) gene product primarily regulates iron uptake into cells by interacting with the TfR to restrict Tf binding (Feder etal., 1998). Genetic variants of the HFE gene are unable to maintain iron homeostasis, and in particular, the H63D variant has been under investigation as a potential risk factor for neurodegenerative diseases. Several studies have reported an increased frequency of the $\mathrm{H} 63 \mathrm{D}$ mutation in $\mathrm{AD}$ patients (Moalem et al., 2000; Sampietro et al., 2001; Combarros et al., 2003; Pulliam et al., 2003; Connor and Lee, 2006). Pulliam et al. (2003) found increased levels of markers of oxidative stress in individuals with HFE mutations compared to controls. The H63D mutation was expressed $\sim 5$ times more frequently in $\mathrm{AD}$ patients younger than 70 years compared to patients over 80 (Sampietro et al., 2001). Indeed, MRI studies revealed increased accumulation of iron in carriers of HFE mutations (Nielsen et al., 1995; Berg et al., 2000). Studies have shown that iron staining is most dense in the proximity of amyloid beta $(A \beta)$ plaques and in cells associated with plaques (Connor et al., 1992b) and that iron promotes deposition of $\mathrm{A} \beta$ (Rottkamp et al., 2001). Interestingly, a similar pattern was observed with respect to HFE expression in AD brains, suggesting HFE expression may be increased in cells in the vicinity of the plaque. A normal response of HFE is to limit iron uptake thus these cells may 
be trying to limit iron uptake; a function that would be compromised if the mutant protein is expressed (Connor and Lee, 2006).

\section{HFE GENE AND VARIANTS}

HFE (high iron), originally called HLA-H, is a major histocompatibility complex (MHC) class I-like gene. It is located on the short arm of chromosome 6 and was first identified by Simon et al. (1976) in association with an iron overload disorder called hereditary hemochromatosis $(\mathrm{HH})$. The HFE gene encodes a $49 \mathrm{kDa}$ membrane glycoprotein that resembles the MHC-class1 family of proteins. The three most common single nucleotide polymorphisms (SNPs) in the HFE gene are H63D ( rs1799945 in exon 2), C282Y ( $r$ s 1800562 in exon 4), and S65C (Merryweather-Clarke et al., 2000; Le Gac et al., 2001). Examination of the frequency and global distribution of HFE mutations indicated that HFE variants are most common in Caucasian populations with a frequency of up to $25 \%$ for H63D, $12 \%$ for C282Y, and $1.6-5.5 \%$ for S65C. S65C is not as common as the other two variants (Camaschella et al., 2002) and has not been associated with physiological changes or diseases (Le Gac et al., 2001).

Not only are the H63D and C282Y variants prevalent, epidemiological evidence associates them with several neurodegenerative, metabolic diseases, and malignancies. Though C282Y is less prevalent in the general population than $\mathrm{H} 63 \mathrm{D}$, it is strongly associated with $\mathrm{HH}$ and recently was identified as a risk factor for prostate, breast, colorectal, and brain tumors (Shaheen et al., 2003; Syrjakoski et al., 2006; Osborne et al., 2010; Gannon et al., 2011). It has also been found to protect against neurodegenerative diseases (Buchanan et al., 2002; Correia et al., 2009). In contrast, the H63D variant was identified as a risk factor for several diseases such as AD (Moalem et al., 2000; Sampietro et al., 2001; Combarros et al., 2003; Pulliam et al., 2003; Percy et al., 2008), amyotrophic lateral sclerosis (ALS; Wang et al., 2004; Goodall et al., 2005), and stroke (Ellervik et al., 2007).

\section{FUNCTION OF HFE}

The best characterized function of HFE is its role in regulation of cellular iron uptake which it mediates by binding to the TfR. Binding affinity of HFE for TfR is comparable to the binding affinity of iron-loaded transferrin (holotransferrin; Feder et al., 1998). When a cell has enough iron, the HFE competitively binds to the TfR at the same site as iron-loaded Tf molecules thereby preventing iron uptake via endocytosis. Formation of the HFE-TfR complex is $\mathrm{pH}$-dependent, with a neutral $\mathrm{pH}$ allowing tight binding and an acidic pH inhibiting it (Lebron et al., 1998, 1999). HFE can prevent endocytosis of TfR alone by inducing its phosphorylation. This results in higher expression of cell surface TfR than is found intracellularly (Salter-Cid et al., 2000).

The function of HFE in iron regulation is disrupted by mutations causing formation of the H63D- and C282Y-HFE variants. It has been shown that while WT-HFE bound to TfR allows only one iron bound $\mathrm{Tf}(\mathrm{Fe}-\mathrm{Tf})$ to bind per TfR and be taken up by cells (Lebron et al., 1998, 1999), H63D-HFE allows uptake of more than one molecule of Fe-Tf because it does not reduce the affinity of Fe-Tf for TfR. Because C282Y-HFE is retained in the trans-golgi complex due to its inability to bind $\beta 2 \mathrm{M}$ and be transferred to the cell surface, it does not interact with TfR, thus resulting in more iron uptake than WT-HFE (Feder et al., 1997; Waheed et al., 1999, 2002). In sum, both variants are associated with cell and tissue iron-overload. For more details see Connor and Lee (2006).

In addition to the increased iron accumulation seen in cells expressing H63D-HFE (Lee et al., 2007; Mitchell et al., 2009b), disruption of mitochondrial potential (Lee et al., 2007), increased influx of intracellular $\mathrm{Ca}^{2+}$ (Mitchell et al., 2009b), increased glutamate uptake (Mitchell et al., 2009b), increased secretion of monocyte chemoattractant protein-1 (MCP1) that has a role in neuroinflammation (Mitchell et al., 2009a), increased ER stress (Liu et al., 2011), increased oxidative stress (Lee et al., 2007), increased toxicity to $A \beta$ (Mairuae et al., 2010), and decreased Pin 1 activity (Hall et al., 2010) that contributes to increased Tau phosphorylation (Hall et al., 2011) are also found. These findings demonstrate that the expression of H63D-HFE creates a permissive milieu for processes that can influence other pathways in neuronal cells such as lipid homeostasis, neurotransmission, and myelination that may ultimately lead to $\mathrm{AD}$.

\section{LIPID DYSHOMEOSTASIS IN NEURODEGENERATIVE DISEASES CHOLESTEROL METABOLISM IN THE BRAIN}

Cholesterol is an essential component of all cell membranes and is needed for maintaining their structure and fluidity. It is required for growth and replication of mammalian cells, exo- and endocytosis, and is a precursor of steroid hormones and bile acids. Cholesterol is synthesized in the liver through a series of reactions with the rate-limiting step catalyzed by HMGCoAR which catalyzes conversion of HMG-CoA to mevalonic acid. Cholesterol is transported to organs other than the brain in the form of lipoproteins. In the brain, almost all of its cholesterol is synthesized in situ, with little to none taken up from the circulation. The insulation of brain from changes in circulating cholesterol is achieved by the blood-brain barrier (BBB). The highest rate of cholesterol synthesis in the CNS occurs during early stages of development especially when myelination is occurring (Jurevics and Morell, 1995, 1997). The mature brain continues to synthesize cholesterol but at lower levels (Mcmillan et al., 1972; Boyles et al., 1985). The finding that the half-life of cholesterol in the adult human brain is approximately 5 years, indicates that it must have an efficient cholesterol recycling mechanism (Bjorkhem et al., 1998).

In the brain, oligodendrocytes, astrocytes and neurons are capable of synthesizing cholesterol (Saito et al., 1987; Suzuki et al., 2007). Most of the cholesterol synthesized by oligodendrocytes is found in myelin. Neurons have a high need for cholesterol due to membrane turnover during synaptic transmission. Instead of synthesizing their own, neurons obtain most of their cholesterol from astrocytes (Srivastava et al., 1997; Stone et al., 1997) which when packaged with ApoE, also synthesized by astrocytes (Pitas etal., 1987a,b; Schmechel, 1993; LaDu, 1998; Dolev and Michaelson, 2004), is delivered to neurons where it is bound by cell surface lipoprotein receptors such as low density lipoprotein receptor (LDLR) and LDLRrelated protein 1 (LRP1) that recognize ApoE prior to endocytosis. Though other apolipoproteins are also found in the CNS, i.e., 
Apo AI, ApoJ, ApoD, evidence suggests that ApoE is highly abundant in the brain and is responsible for the shuttling of cholesterol between astrocytes and neurons (Bjorkhem and Meaney, 2004). A schematic depicting cholesterol metabolism in the CNS is shown in Figure 1.

In addition to recycling of cholesterol, there is need for removal of excess cholesterol from the brain. Due to its hydrophobic nature, cholesterol cannot cross the BBB. Two mechanisms have been proposed for its removal; cholesterol hydroxylation and ApoEdependent efflux. The presence of ApoE-bound cholesterol in the CSF indicates that some excretion of brain cholesterol occurs this way but the mechanism is not understood. Based on the rate of CSF renewal and the amount of cholesterol found in the CSF, it has been estimated that 1-2 mg cholesterol may be eliminated from the brain via the CSF each day (Pitas et al., 1987a). The major mechanism of cholesterol clearance from the brain is its conversion by the enzyme cholesterol 24-hydroxylase (CYP46A1) to 24Shydroxycholesterol (24S-HC), a metabolite that can traverse the BBB (Lutjohann et al., 1996; Bjorkhem et al., 1997, 1998). Introduction of the hydroxyl group in the side chain of the cholesterol molecule causes a rearrangement of membrane phospholipids that allows excretion of the oxysterol in an energetically favorable manner (Kessel et al., 2001). The direction of movement is mediated by the concentration gradient (Bjorkhem and Meaney, 2004). Because almost all of the 24 S-HC originates from the brain, it has been suggested that it can be used as a marker of brain cholesterol homeostasis. Consistent with this view, a number of studies have shown altered levels of 24S-HC in the CSF or plasma of patients with neurological diseases such as AD and multiple sclerosis (MS; Bretillon et al., 2000a; Lutjohann et al., 2000; Leoni et al., 2002). These studies also highlight the importance of a normal flux of cholesterol across the CNS that for healthy humans is approximately $0.09 \mathrm{mg} /$ day per $\mathrm{kg}$ (Saito et al., 1987) and $1.4 \mathrm{mg}$ /day per kg in mice (Panzenboeck et al., 2002). In people with AD cholesterol efflux across the CNS is elevated and is proportional to the severity of dementia (Pfrieger, 2003a). A similar trend was observed in a mouse model of Niemann Pick C1 disease (NPC1), where the increase in cholesterol efflux from the brain was associated with increased neurodegeneration (Panzenboeck et al., 2002).

\section{ROLE OF CHOLESTEROL IN THE BRAIN}

Two major functions for cholesterol in the nervous system are in myelination and synaptic transmission. In addition, it is an essential constituent of cellular membranes and of detergent insoluble lipid rafts, areas enriched in sphingolipids and proteins involved in signal transduction, where it can influence signal transduction and cellular processes. The importance of cholesterol in the brain is evident from the fact that it has $~ 25 \%$ of the body's cholesterol (Bjorkhem and Meaney, 2004). In the brain, cholesterol is enriched in myelin (i.e., oligodendroglia) and is an essential component of membranes of all cells. Notably, myelin consists of $\sim 70 \%$ lipids [mostly cholesterol, phospholipids, and glycosphingolipids (GSLs), i.e., galactocerebroside in molar ratios of 4:4:2] and 30\% proteins (Bjorkhem and Meaney, 2004). The high lipid content of myelin is consistent with the membrane properties required for its role in supporting saltatory conduction. Myelin is produced by oligodendrocytes (Miller, 2002) and cholesterol enrichment in myelin reduces permeability to ions allowing the action potential to move down the axon without diffusing across the membrane (Bjorkhem and Meaney, 2004). It has been shown that a high cholesterol content is needed for proper myelination (Saher et al., 2005). A deficiency in oligodendrocyte cholesterol synthesis was shown to delay proper myelination (Marcus and Popko, 2002; Saher et al., 2005) and to be crucial for the development and maintenance of myelin membranes (Colognato et al., 2002; Gielen et al., 2006; Debruin and Harauz, 2007). Low cholesterol levels in an aging brain could contribute to the loss of myelination that Bartzokis (2011) postulated was an underlying cause of multiple degenerative brain disorders.

Cholesterol content of a membrane regulates its fluidity with greater amounts of cholesterol making them more rigid and lesser amounts making them more fluid and allowing more permeability to ions (Barenholz, 2002). Therefore, disruption of cholesterol distribution in the membrane can affect its function in maintaining normal cell activity. Consistent with this view, altered dendritic

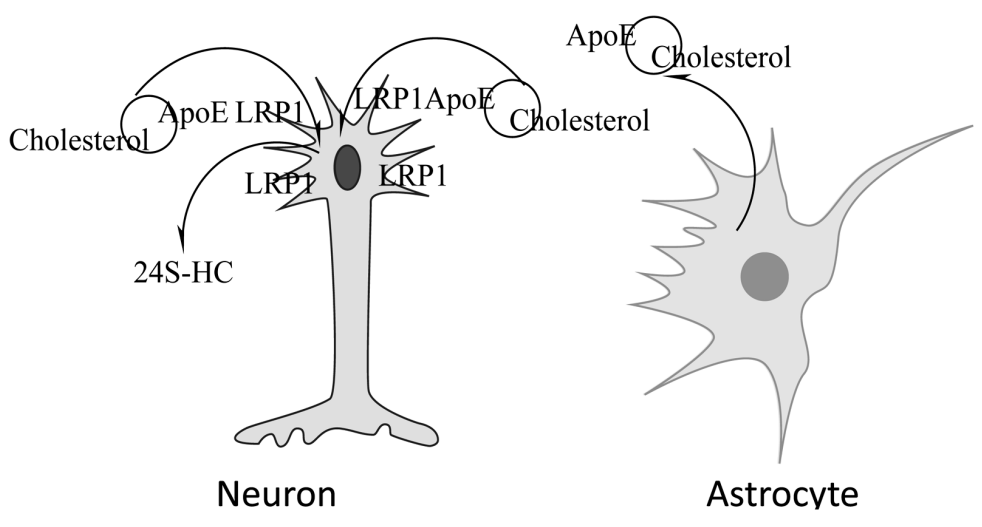

FIGURE 1 | Neuronal acquisition/loss of cholesterol. Cholesterol synthesized by astrocytes is packaged in lipoproteins containing ApoE, released from the cell and taken up by neurons via the lipoprotein receptor-related protein 1 (LRP1)-mediated endocytosis. Cholesterol can be removed by conversion to 24S-hydroxycholesterol, a compound that can cross the BBB, by the action of cholesterol 24-hydroxylase. 
morphology was observed upon depletion of membrane cholesterol in cultured neurons (Holtzman et al., 1995). Disruption of lipid homeostasis significantly alters CNS structure and function possibly by affecting the composition of lipid rafts found in neurons, astrocytes, and oligodendrocytes (Tsui-Pierchala et al., 2002; Gielen et al., 2006; Debruin and Harauz, 2007). Changes in cholesterol concentration can also affect cell surface availability of the carbohydrate moieties of GSLs (Novak et al., 2013) which in turn might affect a cell's ability to respond to GSL-carbohydrate binding proteins.

Several studies have shown that cholesterol is needed for endoand exocytosis and plays a crucial role in synapse structure and function (Pfrieger, 2003b; Takamori et al., 2006). Consistent with this, cholesterol is enriched in presynaptic terminals and its pharmacological depletion reduces synaptic transmission (Suzuki et al., 2004). Several key synaptic proteins such as synaptophysin and the soluble NSF attachment protein receptor (SNARE) proteins are either predominantly found in lipid rafts or must be recruited into them in order to effectively interact with other proteins to promote neurotransmitter release and transmission. These effects are thought to be mediated by direct interaction of cholesterol with synaptophysin (Thiele etal., 2000), and formation of the SNARE complex is cholesterol-dependent (Lang et al., 2001; Mitter et al., 2003). Moreover, Suzuki et al. (2007) showed that an increase in the cholesterol content of lipid rafts, induced by treatment with brain derived neurotropic factor (BDNF), resulted in increased expression of raft-associated presynaptic proteins, changes associated with synapse development. Collectively, these studies highlight the importance of cholesterol in regulating expression of synaptic proteins and for synaptic transmission.

\section{BRAIN vS. PLASMA CHOLESTEROL IN AD}

Findings regarding cholesterol content in the plasma of aging and $\mathrm{AD}$ individuals are inconsistent with regards to whether elevated or lower serum cholesterol is a risk factor for AD. A consistent observation in human studies is that high serum cholesterol in mid-life can increase the risk of developing $\mathrm{AD}$ later in life, but is associated with improved cognition in elderly individuals (Schreurs, 2010). Similarly, lower total serum cholesterol (Kim et al., 2002) and lower high density lipoprotein (HDL) cholesterol were found to be associated with poor cognition in the elderly (Atzmon et al., 2002). However, status of brain cholesterol could be a better predictor of $\mathrm{AD}$ pathogenesis. With regard to the exchangeability between serum and brain cholesterol, the idea that under normal conditions cholesterol from serum does not cross the BBB into the brain is well-established. Support for this concept was provided by studies showing no incorporation of label into lipids of the brain or spinal cord after administration of $\mathrm{D}_{2} \mathrm{O}$ to adult rats (Waelsch et al., 1940). These findings have been replicated by several investigators (Jurevics and Morell, 1995; Dietschy and Turley, 2001). Intravenous injections of ${ }^{14} \mathrm{C}$-labeled cholesterol into healthy volunteers and pregnant women resulted in no label being found in the brains of the healthy volunteers (Meaney et al., 2001) or fetal brain tissue (Plotz et al., 1968), emphasizing that almost all cholesterol in the brain comes from de novo synthesis with little to none from plasma under normal physiological conditions. Surprisingly, brain endothelial cells have been shown to take up a small amount of LDL cholesterol via LDL receptors expressed on their luminal surface (Dehouck et al., 1994, 1997). It has been hypothesized that uptake of small amounts of plasma lipoproteins into the CNS could occur at levels too low to be detected by current methods (Dietschy and Turley, 2001). However, significant uptake of cholesterol from plasma could occur under pathological conditions where the integrity of the $\mathrm{BBB}$ is compromised or in cases of chronic hypercholesterolemia. This possibility is supported by studies showing a number of metabolic changes in the brains of individuals/experimental animals fed diets high in cholesterol. Currently, knowledge is limited in this respect and further studies are needed to elucidate the effects of dietary cholesterol on brain cholesterol, especially in cases of neurological disease.

\section{CHOLESTEROL HOMEOSTASIS AND AD PATHOLOGY}

There is substantial epidemiological, genetic, and molecular evidence of disruption of cholesterol homeostasis in AD (Shobab et al., 2005; Sjogren etal., 2006). Mutations in several genes involved in cholesterol uptake, such as LRP and the very-lowdensity lipoprotein (VLDL) receptor (Zerbinatti and Bu, 2005), as well as in enzymes that regulate cholesterol catabolism such as Cyp46A1 (Wolozin, 2003; Vaya and Schipper, 2007), have been associated with increased risk of AD. In addition epidemiological studies revealed increased susceptibility to $\mathrm{AD}$ in patients with elevated plasma cholesterol levels in mid-life (Jarvik et al., 1995; Notkola et al., 1998; Roher et al., 1999). However, studies of cholesterol in brains obtained from animals with AD symptoms and $\mathrm{AD}$ human brain autopsy tissue have yielded inconclusive results regarding whether high or low brain cholesterol is a risk factor for AD. The lack of agreement between studies could be due to analysis of cholesterol content from different regions/domains, i.e., total brain cholesterol vs. membrane cholesterol vs. cholesterol in lipid raft domains. It has been reported that while the asymmetric distribution of cholesterol in the plasma membrane of aged mice was reduced relative to that of younger mice, total membrane cholesterol was unaltered (Igbavboa et al., 1996). However, cholesterol content of lipid rafts from brains of older mice expressing either human ApoE3 or ApoE4 was greater than in those from brains of younger animals (Igbavboa et al., 2005). It has also been reported that brain cholesterol increases in certain conditions with age, i.e., NPC1 (Vance, 2006) while studies of other conditions provided evidence for a decline in total brain cholesterol, i.e., AD (Ledesma, 2003) and Huntington's disease (Valenza et al., 2005). In addition to total brain cholesterol, maintenance of cellular cholesterol content is crucial in mediating APP processing via alpha and gamma secretases (Bogdanovic et al., 2002; Cam and Bu, 2006) and therefore has physiological relevance to AD. Ginsberg et al. (1993a,b) have shown that in AD brains cell membranes are less stable due to altered lipid composition. In sum, experimental studies have shown that either abnormally high or low cholesterol can be associated with pathogenic manifestations seen in neurological diseases. Excessive loss of brain cholesterol would be expected to be particularly devastating because the rate of cholesterol synthesis in the brain decreases with age and under normal conditions there is no influx of cholesterol from the plasma into the brain.

ApoE is a major apolipoprotein and cholesterol carrier in the brain (Mahley, 1988). It is synthesized and secreted primarily from 
astrocytes as part of small dense cholesterol containing lipoproteins (Pitas et al., 1987a,b; Schmechel, 1993; LaDu, 1998; Dolev and Michaelson, 2004). Neurons take up astrocyte-released ApoE via LRP1 mediated endocytosis (Herz, 1988; Jeon and Blacklow, 2005). In humans, ApoE exists as three isoforms (E2, E3, E4; Mahley, 1988). The association of ApoE4 as a strong risk factor for AD has been well established (Mahley, 1988; Corder, 1993; Mahley et al., 2006). Despite advances in understanding how ApoE functions, the molecular mechanisms by which ApoE4 contributes to $\mathrm{AD}$ are not completely understood. In the general population, ApoE3 is the most common isoform (allele frequency 77-78\%), followed by ApoE4 (15\%; Mahley, 1988). However, ApoE4 is present in $\sim 40 \%$ of $\mathrm{AD}$ patients (Corder, 1993). Isoform-specific effects in cholesterol transport were observed with ApoE4 being less efficient than ApoE3 (Michikawa et al., 2000; Gong, 2002; Rapp et al., 2006). There is also evidence that ApoE3-expressing astrocytes can supply more cholesterol to neurons than those expressing ApoE4 (Gong, 2002). Recent reports about the ability of neurons to recycle ApoE and retain ApoE inside cells (Fazio et al., 2000) have led to the hypothesis that ApoE may play additional roles in mediating cell signaling and intracellular-homeostasis. One proposed role, that of an antioxidant, is based on its ability to bind metals such as copper, iron, and zinc, with its highest binding affinity being for iron (Miyata and Smith, 1996). Interestingly, the antioxidant and metal binding activities of ApoE were found to be allele-specific, with ApoE4 less efficient in binding metals (Mutter et al., 2004) and reducing oxidative stress than ApoE3 (Miyata and Smith, 1996).

\section{SPHINGOLIPIDS IN NEURODEGENERATIVE DISEASES}

Sphingolipids contain sphingosine as their basic building block and are enriched in lipid rafts. When substituted with a fatty acid in an amide linkage on $\mathrm{C} 2$, ceramide is produced that when linked to phosphorylcholine yields sphingomyelin and when glycosylated yields a GSL. Sphingolipids function in cell-cell recognition, signaling cascades that result in cell proliferation, apoptosis, stress responses, inflammation, differentiation, and axon growth (Venable et al., 1995; Hannun and Obeid, 2002; Spiegel and Milstien, 2002; Lavieu et al., 2006; Snider et al., 2010). Unequivocal evidence for the need for appropriate synthesis of sialylated GSLs was provided by the finding that brains of children who lacked the ability to synthesize GM3 failed to develop normally (Simpson et al., 2004). Dysregulation of GSL metabolism has also been implicated in a number of metabolic and neurological diseases such as Fabry disease, Krabbe disease, Gaucher disease, Tay-Sachs disease, Metachromatic leukodystrophy, Niemann-Pick disease, AD (Haughey et al., 2010; He et al., 2010; Ryland et al., 2011).

Several studies have shown abnormalities in the lipid content and expression of enzymes regulating their content in AD brains. For example, the total phospholipid and sulfatide content in AD brains was decreased compared to that in controls (Skinner et al., 1989; Soderberg et al., 1992; Gottfries et al., 1996; Pettegrew et al., 2001; Han etal., 2002; Cheng et al., 2003). On the other hand, ceramide, a pro-apoptotic lipid was found to be elevated in the brains (Cutler et al., 2004) and CSF of patients with AD (Satoi et al., 2005). Ceramide can be produced by hydrolysis of sphingomyelin via sphingomyelinases, or by de novo synthesis from fatty acyl CoA and sphingosine. It has been proposed that oxidative stress and other age-related factors contribute to the age-related accumulation of ceramide and induction of apoptotic signaling in neurons and other cells (Kolesnick and Kronke, 1998; Cutler et al., 2004; Costantini et al., 2005; Perez et al., 2005). He et al. (2010) replicated the findings of a reduction in sphingomyelin and an elevation of ceramide in AD brains made by Satoi et al. (2005). In addition, they also found reduced levels of sphingosine-1-phosphate (S1P), a pro-survival metabolite, which correlated significantly with the levels of $\mathrm{A} \beta$ peptide and hyperphosphorylated tau protein $(\mathrm{He}$ et al., 2010).

In addition to the sphingolipids mentioned above, the relationship of gangliosides, a sub-class of GSLs, to AD pathogenesis has been investigated. Gangliosides are found in their highest concentration in the gray matter of the brain, with GM1, GD1a, GD1b, and GT1b accounting for $65-85 \%$ of them (Schengrund, 2010). Interestingly, total ganglioside content was found to be reduced in most regions of brains from early onset or familial cases of $\mathrm{AD}$, while in cases of late-onset or sporadic $\mathrm{AD}$, ganglioside reduction was observed only in the temporal cortex, hippocampus and frontal white matter (Svennerholm and Gottfries, 1994). These observations suggest an age-dependent and/or regionspecific pattern of distribution that could be differentially altered in $\mathrm{AD}$.

Though reduction of total brain ganglioside levels in $\mathrm{AD}$ has been reported, significant elevation of certain ganglioside species has also been consistently reported. For example, GM1, one of the major gangliosides in brain that is enriched in lipid rafts, was found to be significantly elevated in brains of AD patients (Svennerholm and Gottfries, 1994) and, in lipid rafts isolated from their frontal and temporal cortices (Molander-Melin et al., 2005) A similar observation was made in a neuroblastoma cells expressing the H63D-HFE variant (Ali-Rahmani et al., 2014a) suggesting these changes are driven by HFE genotype and that a model for determining the mechanism for HFE impact on lipid rafts exists

Additional support for the role of gangliosides in AD was provided by the observation that GM1 stimulated production of $A \beta$ by increasing $\gamma$-secretase activity (Zha et al., 2004), that it binds to A $\beta$ with high affinity (Ariga et al., 2001), and could serve as a "seed" for $A \beta$ aggregation by promoting formation of toxic $A \beta$ fibrils (Choo-Smith et al., 1997; Yanagisawa, 2005; Kimura and Yanagisawa, 2007; Okada et al., 2007; Yamamoto et al., 2007). Indeed, GM1 was found bound to $A \beta$ in amyloid plaques in $A D$ brains (Hayashi et al., 2004). It has also been shown to influence AD pathogenesis by altering calcium homeostasis. It has been shown that plasma membrane-associated GM1 can enhance intracellular $\mathrm{Ca}^{2+}$ levels by increasing influx of extracellular $\mathrm{Ca}^{2+}$ (Ledeen and Wu, 2002; Wu et al., 2007) which might affect calcium-mediated phosphorylation of tau and APP (Schengrund, 2010). In addition to affecting APP and $\mathrm{Ca}^{2+}$ homeostasis, GM1 has been found to be associated with altered content of other lipids such as cholesterol. Molander-Melin et al. (2005) reported that an elevation of GM1 and GM2 in lipid rafts isolated from AD brains was associated with a concomitant decrease in their cholesterol (Molander-Melin et al., 2005). Similarly, pharmacological depletion of cholesterol in murine neuroblastoma cells resulted in a significant elevation 
in the recognition of GM1 (Petro and Schengrund, 2007), suggesting an inverse relationship between GM1 and cholesterol. The fact that both lipids are present in rafts supports the hypothesis that significant changes in either or both could affect the ability of rafts to modulate a number of cellular processes affecting neuronal function. Collectively, these studies show that sphingolipids play important roles in AD pathogenesis. Further elucidation of factors that can influence sphingolipid composition is needed. Factors inducing oxidative stress such as iron are potential targets. Future investigation in this area will further our understanding of the connection between iron and lipid metabolism and will help in development of better treatment strategies.

\section{LIPID RAFTS IN AD}

Given the abundance of cholesterol and sphingolipids in the brain, lipid rafts have been proposed as critical for regulating processes such as neuronal signaling, neuronal cell adhesion, axon guidance and neurotransmission required for normal brain function. Rafts have been shown to facilitate intramembrane proteolysis to activate or inactivate several transmembrane proteins such as APP and receptors involved in neurotrophin signaling (Landman and Kim, 2004; Vetrivel et al., 2005). In addition, ionotropic receptors, pre-synaptic SNARE complex proteins (i.e., synaptophysin), as well as, post synaptic receptors [such as $N$-methyl-D-aspartic acid (NMDA) and gamma-aminobutyric acid (GABA)], and key proteins involved in myelination (i.e., CNPase, MBP) are known to localize in lipid rafts and modulation of lipid raft composition has been shown to affect their function (Marta et al., 2004; Stetzkowski-Marden et al., 2006; Willmann et al., 2006; Besshoh et al., 2007; Huang et al., 2007). Changes in the composition of rafts by depletion of cholesterol or sphingolipids can affect the structure (assembly and disassembly) and function of lipid rafts and ultimately, cellular phenotype (Keller et al., 2004; Veatch and Keller, 2005). Evidence is also accumulating to support the concept that there is a dynamic equilibrium between cholesterol and sphingolipids within the rafts and that when levels of one of these components is altered it affects the concentration of the other (Ali-Rahmani et al., 2011).

The roles of lipid rafts in the brain have been under intense investigation, particularly in the context of neurodegenerative diseases. Relevant to $\mathrm{AD}$ are studies showing loss of lipid rafts in the temporal cortex (Molander-Melin et al., 2005) and reduced cholesterol in rafts isolated from hippocampi of AD patients (Ledesma, 2003; Abad-Rodriguez et al., 2004). These observations are consistent with findings of significant loss of total brain cholesterol in advanced stage AD patients (Abad-Rodriguez et al., 2004). Studies focused on investigating the role of lipid rafts and their cholesterol content in amyloidogenesis have yielded conflicting results. Analyses of the effect of changes in the cholesterol content of lipid rafts, sites where APP and presenilin-1 (enzyme that cleaves APP to generate toxic $A \beta$ ) localize or are recruited to in order to promote amyloidogenesis, indicated that a high cholesterol content favored it (Bouillot et al., 1996; Lee et al., 1998; Morishima-Kawashima and Ihara, 1998; Hayashi et al., 2000). In contrast studies in which cholesterol was depleted from neuronal cells expressing human APP resulted in colocalization of presenilin-1 and APP in nonraft domains and increased $\mathrm{A} \beta$ production (Abad-Rodriguez et al.,
2004). These findings along with the evidence of low total brain cholesterol in AD patients support the hypothesis that therapeutic approaches designed to lower brain cholesterol could be detrimental to normal brain function. In fact, accumulating evidence indicates that loss of cholesterol can promote neurodegeneration as lower serum/total brain/membrane cholesterol have been implicated in increased risk of Parkinson's (Du et al., 2012), ALS (Albert, 2008; Chio et al., 2009), Smith-Lemli-Opitz syndrome (Jira et al., 2003), Huntington's (Valenza et al., 2005), Alzheimer's (Ledesma, 2003; Wellington, 2004; Wolozin, 2004), and Niemann-Pick Type C (Vance, 2006) diseases. In summary, lipid rafts modulate a number of cellular processes that affect neuronal function and alterations in their composition (cholesterol and sphingolipid content) can influence cellular phenotype. Investigation of lipid rafts in the context of iron related disorders such as $\mathrm{HH}, \mathrm{AD}$, and iron deficiency anemia are exciting new areas of research which should be further explored to unravel potential signaling pathways underlying iron related disorders that might be treated by modulation of the lipid composition of rafts.

\section{IS THERE A LINK BETWEEN IRON AND CHOLESTEROL METABOLISM?}

Contribution of iron to neurodegeneration in $\mathrm{AD}$ has also been proposed to occur based on its ability to influence four pathways implicated in AD: (1) APP metabolism (Mantyh et al., 1993; Bodovitz et al., 1995; Schubert and Chevion, 1995; Rottkamp et al., 2001; Rogers et al., 2002; Kuperstein and Yavin, 2003), (2), the loss of calcium homeostasis (Hidalgo and Nunez, 2007), (3) the degradation of a subset of microglia (Lopes et al., 2008), and (4) oxidative stress (Honda et al., 2004; Liu et al., 2006; Smith, 2006; Castellani et al., 2007, 2012). Here we propose that the effect of iron on lipid metabolism is also a potential contributor to $\mathrm{AD}$.

Despite the efforts that have been made to identify factors that can trigger the pathological events associated with $\mathrm{AD}$ the sequence of events is still not clear. Accumulation of $A \beta$ has been thought to be the triggering event, preceding NFT formation, and ultimately culminating in synaptic failure and memory impairment. However, other evidence indicates that tau pathology may precede formation of amyloid plaques. The evidence of memory decline accompanied by symptoms characteristic of $\mathrm{AD}$, in the absence of amyloid plaques and/or NFTs, supports questioning whether these pathological markers are the only causative agents. Since molecular phenotypes such as oxidative stress, synaptic failure, neuronal loss, and cognitive decline, characteristics associated with $\mathrm{AD}$, have been shown to result from disruption of a number of the pathways discussed above, one can easily argue that there is no linear sequence of events that causes AD. A good example of an interconnection between pathways that may have relevance to $\mathrm{AD}$ lies at the intersection between iron and cholesterol metabolism. Both iron and cholesterol metabolism have been independently implicated in the etiology of $\mathrm{AD}$ as described above. A large number of studies have established that disruption of cholesterol metabolism is associated with multiple aspects of $\mathrm{AD}$, including APP metabolism, Tau phosphorylation, synaptic integrity and transmission, and cognitive function. Iron dyshomeostasis has also been shown to contribute to the above-mentioned aspects 
of $\mathrm{AD}$, suggesting an interactive cross-talk between the two pathways that may result in synergistic deleterious effects contributing to the development of AD. Evidence is accumulating for a potential link between iron and cholesterol metabolism in the context of atherosclerosis, yet this link and its relevance to AD remains largely unexplored. There is some evidence to support this association. (1) Iron is a required cofactor for a number of enzymes involved in cholesterol metabolism so it is logical to speculate that alteration in iron content could influence the activity of those enzymes. (2) Iron, ApoE, and cholesterol have all been found in association with extracellular amyloid plaques and intracellular neurofibrillary tangles, hallmark features of AD. (3) Iron is a potent source of oxidative radicals that have been consistently reported to affect membrane lipids and thereby influence lipid homeostasis. (4) Rabbits fed a cholesterol-rich diet were found to accumulate iron and $\mathrm{A} \beta$ deposits in the brain, and to have increased mortality (Ghribi et al., 2006). Finally, and perhaps most relevant are the recent findings that carriers of both the ApoE4 (cholesterol transporter) allele and H63D-HFE variant (iron accumulation, cholesterol decrease) had increased risk for and 5.5 year earlier onset of AD (Moalem et al., 2000; Sampietro et al., 2001; Combarros et al., 2003; Percy et al., 2008). Collectively, these studies highlight an area of investigation that could lead to a better understanding of the underlying causes for $\mathrm{AD}$ and impact the $25 \%$ of the Caucasian population that carries at least one H63D allele.

The finding that carriers of both the H63D-HFE and ApoE4 alleles have an earlier onset of AD (Percy et al., 2008) indicates that there is a connection between iron, cholesterol, and $\mathrm{AD}$; however, the interaction of iron and cholesterol and its relevance to AD had not been specifically investigated prior to our studies of the effect of H63D-HFE on both (Ali-Rahmani et al., 2014a). While the H63DHFE-expressing neuroblastoma cells had increased iron content and iron is a required cofactor for a number of enzymes involved in cholesterol synthesis (e.g., HMGCoAR and squalene synthase), the cells expressed less HMGCoAR and had less total cholesterol than WT-HFE-expressing controls. They also had an increased expression of CYP46A1 (Ali-Rahmani et al., 2014a). These observations were recapitulated in studies of the brains of H67D-HFE mice. Brain cholesterol content of H67D-HFE mice was significantly higher in 6 month old mice, however as these mice aged their brain cholesterol content continued to decline much more than in WT-HFE mice (Figure 2). Strikingly, a significant negative correlation was found between brain iron and cholesterol content for H67D-HFE mice ages 12-24 months (Ali-Rahmani et al., 2014a). These mice had higher total brain iron content and lower brain cholesterol content than their wild-type littermates. These results are similar to the association found between increased brain (nigrostriatal) iron content and low serum cholesterol in patients with Parkinson's disease (Du et al., 2012). Though it is believed that cholesterol content of serum is not necessarily reflective of that of brain, it is important to note that in another study it was shown that patients with high serum iron and low serum cholesterol had the highest risk of PD (Powers et al., 2009), indicating the relevance of the interplay between iron and cholesterol metabolism in a neurodegenerative disease.

An inverse relationship between iron and cholesterol content was also observed in several additional studies. For example,

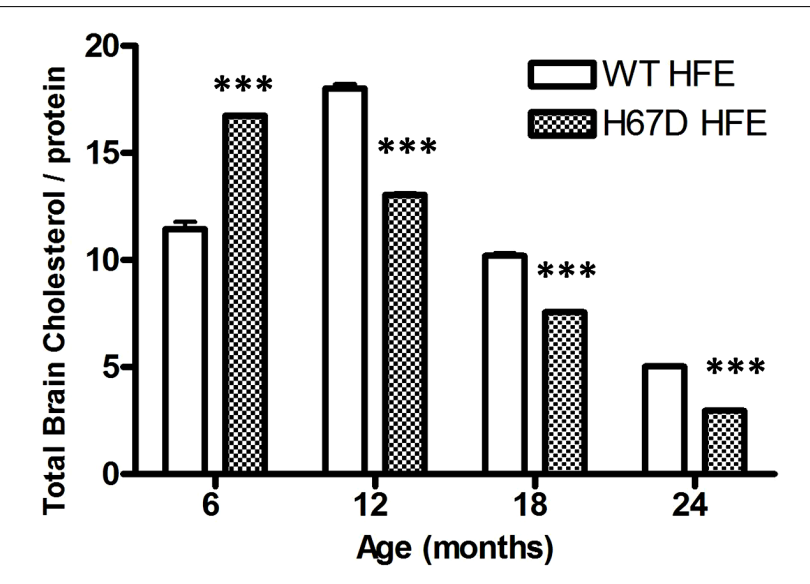

FIGURE 2 | Total brain cholesterol content of mice expressing WT- or H67D-HFE. Brains were dissected from mice at 6, 12, 18, and 24 months. After homogenization, protein concentration was determined by Bradford assay ( $n=7-17$ per group including both male and female mice). Lipids were extracted from $100 \mu$ l of brain homogenate. Cholesterol content was measured by following the manufacturer's protocol (Biovision), and is shown as $\mu \mathrm{g}$ of cholesterol per mg of protein $\left({ }^{* *} p<0.001\right)$. Data were analyzed using a two-way ANOVA followed by Bonferroni tests to compare effects of age and genotype on age-related changes in brain cholesterol of HFE variant mice using Graphpad (Prism) software. Error bars represent the standard error of the mean.

Brunet etal. (1997) found that treatment of rats with an ironsalicylate complex resulted in an elevation of iron, products of lipid peroxidation, and reduced total serum cholesterol. Treatment of rats with an iron dextran complex resulted in an elevation of iron and a decrease in total serum cholesterol regardless of whether the rats were fed a normal diet or one high in cholesterol (Turbino-Ribeiro et al., 2003). Similar results were found in earlier studies in which rabbits treated with an iron dextran complex and fed a normal diet were found to have reduced serum cholesterol (Dabbagh et al., 1997). In fact, diet-induced iron overload resulted in reduced expression of liver HMGCoAR and CYP7A1 (Brunet et al., 1999).

One possible explanation for the effects of a high iron diet is that they are mediated by iron-induced oxidative stress (Dabbagh et al., 1994) and lipid peroxidation (Britton et al., 1987). Depletion of energy (ATP and NADPH) due to oxidative stress and lipid-peroxidation mediated membrane damage were shown to cause disruption of lipid synthesis and transport (Kehrer, 1993). These observations coupled with the inverse relationship between iron and cholesterol described above support the hypothesis that the changes induced in iron and cholesterol by expression of H63D-HFE and possibly additional mediators disrupt the normal neuronal function. One possible molecule involved in these interactions is $A \beta$. The presence of the iron response element (IRE) in the promoter region of the APP gene and the observation of an iron-concentration dependent increase in APP mRNA provides compelling evidence for the role of iron in APP expression and possibly A $\beta$ generation (Bodovitz et al., 1995; Rogers et al., 2002; Rogers and Lahiri, 2004). Interestingly, there is also evidence that $\mathrm{A} \beta$ can, in turn, modulate cholesterol and sphingolipid metabolism by regulating the activities of key lipid enzymes 
(Zinser et al., 2007; Grimm et al., 2012). Specifically, A $\beta$ has been shown to inhibit cholesterol synthesis by inhibiting HMGCoAR (Grimm et al., 2012), suggesting that a feedback mechanism exists between cellular cholesterol and $A \beta$ content. Furthermore, GM1 has been shown to serve as a "seed" for $A \beta$ aggregation into toxic fibrils (Hayashi et al., 2004; Yanagisawa, 2005; Okada et al., 2007). Intriguingly, there is evidence that an increase in GM1, or a change in its accessibility to GM1-binding proteins can occur upon reduction of cellular cholesterol (Lingwood et al., 2011). A link for a relationship between iron, cholesterol, and GM1, was provided by our finding that H63D-HFE human neuroblastoma cells contained more iron (Lee et al., 2007), expressed more cholera toxin binding GM1 (Ali-Rahmani et al., 2011) and had less cholesterol than cells expressing WT-HFE (Ali-Rahmani et al., 2014a). Taken together, our findings and the studies of the role of APP metabolism in $\mathrm{AD}$ and its relationship to either iron or cholesterol, provide the basis for the proposed mechanism (Figure 3 ) by which effects induced by expression of H63D-HFE may lead to the symptoms associated with $\mathrm{AD}$.

With the exception of $A \beta$ content, all of the pathological effects indicated in this model have been observed in either cells expressing H63D-HFE or in the brains of mice expressing H67D-HFE. Cellular studies indicated no difference in the levels of total APP or
$\mathrm{A} \beta$ between WT- and H63D-HFE-expressing cells, but increased sensitivity to $A \beta$ treatment was observed in the latter (Mairuae et al., 2010). Further study of the age-related effects of expression of the H63D variant on APP metabolism in an in vivo model should further define the interrelationships of HFE, APP, iron, and cholesterol metabolism, and the mechanisms by which they may contribute to dementia.

As important as it is to study the impact of iron overload on lipid metabolism, the question of what impact high serum and/brain cholesterol levels might have on iron metabolism in the brain should also be investigated. Such a study might help to explain the (1) established link between hypercholesterolemia and atherosclerosis and the fact that they both are significant risk factors for $\mathrm{AD},(2)$ connection between disruption of iron metabolism and atherosclerosis, and (3) impact of a cholesterol enriched diet on iron management. Results from studies in rabbits that were fed a diet high in cholesterol showed an increase in iron accumulation in the brain (Ong and Halliwell, 2004; Ong et al., 2004; Ghribi et al., 2006) and an elevation of lipid peroxidation products (De La Cruz et al., 2000; Gokkusu and Mostafazadeh, 2003). Though passage of dietary cholesterol into the brain is prohibited by the BBB, some metabolites, small molecules, and inflammatory cytokines produced by chronic hypercholesterolemia may be able

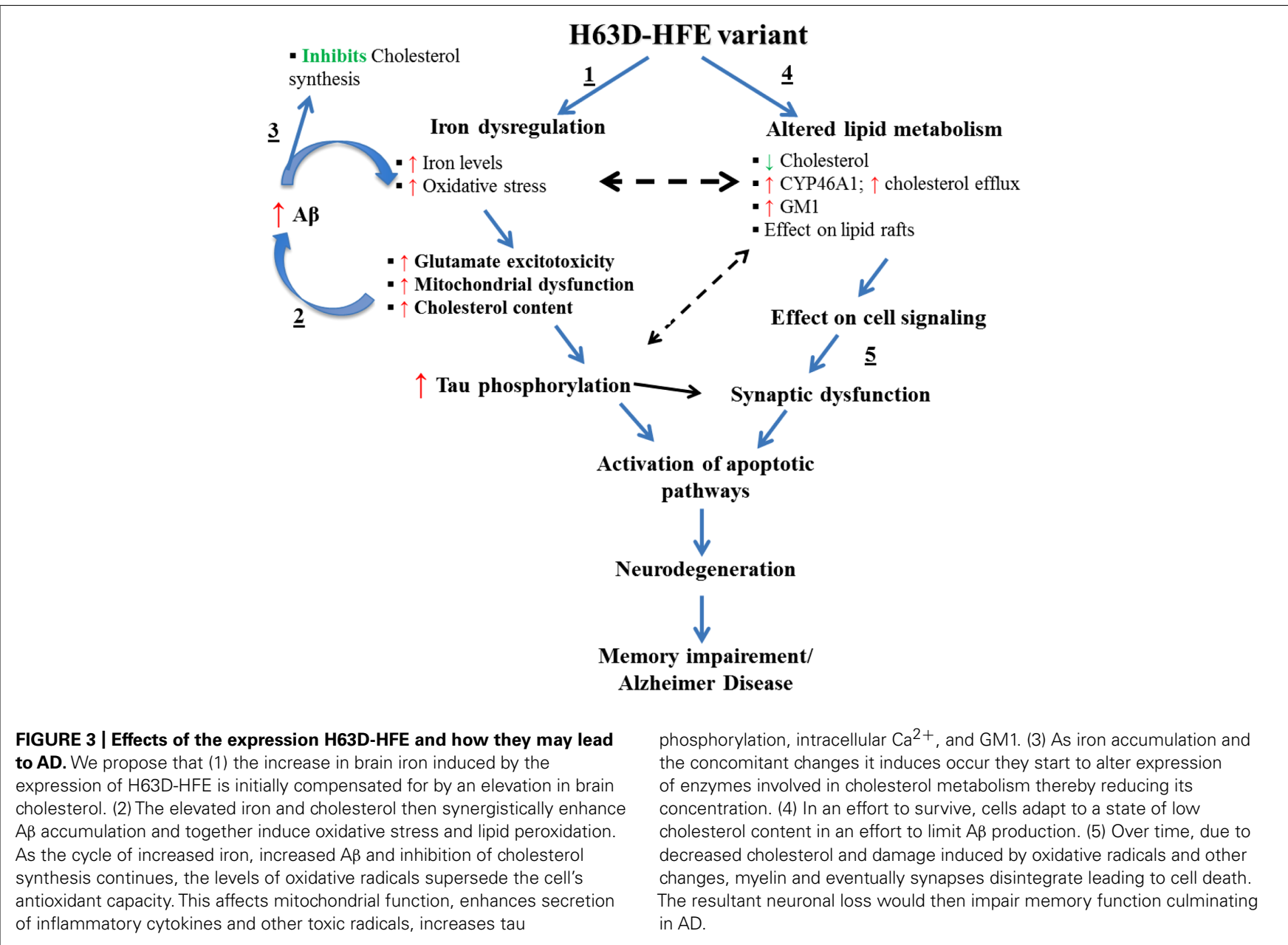


to cross from the circulation into the $\mathrm{BBB}$ and eventually alter the permeability of the BBB to other harmful substances. The observation of iron accumulation in the brain after long-term feeding of a high-cholesterol diet provides support for this argument and raises the question of whether and/or how hypercholesterolemia allows increased passage of iron into the brain parenchyma. The next logical question is then how would individuals with H63DHFE be affected by these changes? We know that individuals with H63D-HFE have elevated iron levels in liver as well as in the brain (Waheed et al., 1997; Adams et al., 2005; Bartzokis et al., 2010). If these individuals develop hypercholesterolemia, they could have even more passage of iron into the brain, more oxidative stress and other disease-associated consequences. Interestingly, it has been shown that individuals with the ApoE4 allele have high serum cholesterol and an increased incidence of hypercholesterolemia. This observation may provide an explanation for why individuals with both ApoE4 and H63D-HFE have an increased risk and earlier onset of AD. Further elucidation of this mechanism would provide an explanation for why atherosclerosis and hypercholesterolemia, conditions prevalent in many aging individuals, may contribute to the development of AD. In relation to that, studies aimed at teasing out the effects of diet (high-iron or high cholesterol, or both) on mice expressing WT-HFE (have normal iron; able to protect cells from iron overload) should yield results indicating the extent to which diet-induced changes affect iron and cholesterol metabolism in the brain.

\section{HOW DOES H63D-HFE AFFECT INTERACTIONS BETWEEN GLIAL AND NEURONAL CELLS?}

Experimental results indicate that H63D-HFE creates a permissive milieu for pathogenic processes (Lee et al., 2007; Mitchell et al., 2009a,b; Hall et al., 2010, 2011; Mairuae et al., 2010; Ali-Rahmani et al., 2011; Liu et al., 2011). These observations raise the question of how the effects of iron accumulation and resulting oxidative stress, elevation of extracellular glutamate, increased secretion of MCP-1 and 24S-HC in one cell type impacts other cells in the brain and vice versa. The importance of this question is highlighted by the characteristic iron-deficient phenotype of macrophages in $\mathrm{HH}$ patients, a puzzle that has not yet been solved. It has been shown that although $\mathrm{HH}$ patients have a significant iron overload in their livers and other organs, their macrophages appear to be iron-depleted (Cardoso and de Sousa, 2003). Consistent with this observation, cell studies have shown that the normal function of WT-HFE is not only to manage iron uptake but to prevent its efflux from cells into the extracellular space (Drakesmith et al., 2002). Because this function is impaired in H63D-HFE cells more iron is released from macrophages (Drakesmith et al., 2002). Considering that microglia in brain function similarly to macrophages in the circulation, expression of H63D-HFE may affect them analogously. If it does, it is likely that H63D-HFE expressing microglia would release more iron than normal and this could affect other cells in the CNS. Support for this is provided by results from a number of studies that examined the effects of iron on cells in the CNS. Zhang et al. (2007) showed that conditioned media from iron-loaded microglia increased survival of oligodendrocytes by delivering iron in ferritin, which could contribute to the proliferative effects on oligodendrocytes. However, lipopolysaccharide
(LPS) activation of iron-loaded microglia attenuated the proliferative effects on oligodendrocytes and caused them to release inflammatory cytokines (Zhang et al., 2007). It has also been shown that microglial activation and secretion of inflammatory cytokines can decrease ferritin synthesis via the modulatory effects of nitric oxide on the iron regulatory system (Chenais et al., 2002). It is logical to argue that a decrease in ferritin along with a preexisting iron-overload and/or increased iron uptake would result in more intracellular free iron that could exacerbate the oxidative damage often seen in neuronal and glial cells in neurological disorders (Rotig et al., 1997; Hirsch and Faucheux, 1998; Smith et al., 1998). So the question is what causes microglial activation? Iron accumulation has been shown to influence glial activation either directly or through induction of other factors such as the MCP-1, a chemokine (Rollins, 1997) shown to cause glial activation (Vrotsos et al., 2009) as well as induction of pro-apoptotic genes and cell death (Zhou et al., 2006). Of particular interest is the finding that cells expressing H63D-HFE have increased secretion of MCP-1 (Mitchell et al., 2009a). Therefore, it is likely that iron accumulation within brain cells affects microglia and this in turn, influences the function of neurons and glia, thereby creating a vicious cycle of events that potentiate stress and damage within the CNS. In such a scenario, endothelial cells, gatekeepers of the BBB, could also be influenced by these changes. In fact, experimental studies have shown that iron accumulation damages endothelial cells by induction of apoptotic pathways (Carlini et al., 2006). Therefore, maintaining iron homeostasis is essential for preserving endothelial function needed to maintain integrity of the BBB. This is crucial for protecting the brain from the harmful effects of chemicals that can be present in the circulation and for maintaining a stable flux of ions into the brain for proper impulse generation and propagation by neurons. The changes in iron and cholesterol induced by expression of H63D-HFE have major effects on the CNS and as such their effects on neuro-glial interactions should be further investigated. For such investigations, the H67D-HFE mouse model could be useful since we found that the animals expressed symptoms associated with human AD (Ali-Rahmani et al., 2014a). Schematic in Figure 3 summarizes findings from in vitro and in vivo studies with H63D variant of HFE. The H67D-HFE mouse model could also be used to study the effects of changes in dietary iron or cholesterol, as well as the effects of statins and iron chelators on learning and memory. Results of such studies could provide insights into how geneenvironmental interactions may contribute to the pathogenesis of AD.

Because endothelial cells of brain microvasculature come in direct contact with the red blood cells (RBCs) and exchange material such as ions, nutrients, etc., with them, it was postulated that characterization of RBCs may provide useful information about the brain metabolism. The changes in the membranes of RBCs could reflect alterations in the brain and such alterations could be used as biomarkers to diagnose and monitor progression of neurological diseases. In fact, morphology of RBCs and the protein composition of $\mathrm{RBC}$ membranes from RBCs isolated from $\mathrm{AD}$ subjects were shown to be altered (Sabolovic et al., 1997; Mohanty et al., 2010). Furthermore, oxidative stress associated changes in the phospholipid content of RBC membranes 
isolated from RBCs from AD patients were observed (Oma et al., 2012) and subsequently a panel of ten plasma phospholipids was shown to predict occurrence of memory impairment in aging individuals (Mapstone et al., 2014). These findings provide support for the hypothesis that RBC lipid dynamics could be important determinants in neurological diseases. Further support for this concept was provided by the observation that RBC membranes from autistic children tended to have reduced cholesterol and increased GM1 relative to those from healthy controls (Schengrund et al., 2012). Based on the finding of similar lipid changes in neuroblastoma cells expressing H63D-HFE, a logical future avenue of investigation would be to compare the lipid and protein composition of RBC membranes from individuals expressing H63D-HFE with those from both healthy people and those with neurological disorders. If indeed a biochemical profile is identified in RBCs from carriers of HFE variants (control, MCI, AD) that is associated with disease pathology, it could be evaluated for its effectiveness as a biomarker to study disease progression. Identification of such a biomarker would significantly aid in future investigations and possibly treatment. Furthermore, the fact that decreased brain cholesterol is associated with disruption of myelin and synapse management as well as cognitive function (Ali-Rahmani et al., 2014a), provides compelling evidence to ascertain whether H63D-HFE is associated with increased risk of developing autism.

\section{POTENTIAL BIOMARKERS FOR AD PROGRESSION}

It is accepted that lipids are crucial for maintenance of normal brain function. However, it is difficult to analyze its lipid content in living individuals. Due to the magnetic properties of iron, brain iron status can be accessed, at least indirectly, by MRI (Bartzokis et al., 1999). However, no such tool is available to monitor the status of brain cholesterol. Owing to the high lipid content of myelin, certain MRI techniques that measure myelination by way of quantifying white matter tracts may provide an idea of lipid status, but no direct conclusions can be made. Because of the difficulty of directly monitoring changes in the brains of living individuals, researchers are searching for potential biomarkers that can be used to identify onset and follow the progression, and response to treatments of neurodegenerative diseases. With respect to brain cholesterol homeostasis, one candidate proposed as an effective biomarker is $24 \mathrm{~S}-\mathrm{HC}$. Almost all 24S-HC found in plasma and CSF originates from the action of a brain specific enzyme, CYP46A1 which catalyzes the first step in the clearance of cholesterol from the brain (Bjorkhem et al., 1998). Results from a number of studies have shown an elevation of 24S-HC either in the CSF or in the plasma of patients suffering from traumatic brain injury or neurodegenerative diseases (Bretillon et al., 2000b; Cartagena et al., 2010). More specifically, it was found that during the early stages of $\mathrm{AD}$ or vascular dementia (Lutjohann et al., 2000) and active periods of MS, high levels of $24 \mathrm{~S}-\mathrm{HC}$ were present in either the CSF or circulation (Leoni et al., 2002), possibly due to ongoing demyelination (Bjorkhem and Meaney, 2004). However, in late stage AD patients' CSF levels of 24S-HC were found to be reduced (Bretillon et al., 2000a; Leoni etal., 2002, 2006; Papassotiropoulos et al., 2002); they were also reduced in the brains of patients who died from $\mathrm{AD}$
(Heverin et al., 2004). The reduction may reflect the extensive neuronal loss seen in late stages of AD. Consistent with these findings, was our observation that expression of the brain-specific enzyme CYP46A1 is elevated in both human neuroblastoma cells expressing H63D-HFE and in the brains of H67D-HFE mice (AliRahmani et al., 2014a). Though the amount of 24S-HC was not measured, the observed concomitant decrease in cellular and total brain cholesterol indicated that it is probable that the expression of H63D/H67D would be associated with higher levels of 24S$\mathrm{HC}$ in serum or CSF or both. It would be useful to confirm this idea using the H67D mouse model. These findings could then provide a rationale for measuring the levels of $24 \mathrm{~S}-\mathrm{HC}$ in the plasma and CSF of individuals carrying H63D-HFE. If a relationship were established between levels of plasma and CSF $24 \mathrm{~S}-\mathrm{HC}$ and incidence or severity of $\mathrm{AD}$, it could be used as a biomarker.

It is also possible that brain volume as determined by MRI could be used as a biomarker for monitoring relative changes in the impact of HFE genotype with normal aging and in disease. This idea is based on the early reports of elevated brain iron in the carriers of H63D (Bartzokis et al., 2010), as well as on reduced volume of brain regions involved in memory in aged H67D-HFE expressing mice, a finding that correlated significantly with the concentrations of brain cholesterol and iron, as well as measures of learning and memory (Ali-Rahmani et al., 2014a). Therefore, these findings suggest that progression of memory decline with normal aging and in patients diagnosed with $\mathrm{AD}$ could be monitored by using volumetric MRI measurements. These tools could also be useful for assessing the efficacy of treatment. In summary, the foregoing discussion supports the hypothesis that $24 \mathrm{~S}-\mathrm{HC}$ and brain volume could be useful for monitoring disease progression and possibly treatment efficacy in carriers of H63D-HFE with a neurodegenerative disease.

\section{IS IT IRON ACCUMULATION OR EXPRESSION OF AN HFE VARIANT THAT IS THE CULPRIT?}

H63D and C282Y are the most common variants of HFE and expression of either results in iron overload. Additionally, a number of other cellular processes are also altered in cells expressing these variants. This raises the question of whether the observed changes result from iron accumulation or occur due to a gain-offunction of the mutation. Epidemiological studies indicate that H63D-HFE is a risk factor for AD and C282Y-HFE for certain cancers. Results in Table 1 summarize previous findings. The fact that both variants of HFE, H63D, and C282Y, are associated with intracellular iron accumulation, yet result in opposing phenotypes, H63D-HFE promoting apoptosis and C282Y-HFE promoting cell survival, indicates that these mutations by themselves could be playing a role independent of their effect on cellular iron status. Supporting this argument are the findings that their subcellular distribution differs. Both WT- and H63D-HFE are found in the plasma membrane, while C282Y-HFE is retained in the ER/golgi. This striking difference is important because the subcellular localization could affect protein-protein interactions and cell signaling. Of potential importance with regard to cell signaling is our observation that while WT-HFE and H63D-HFE were localized in fractions containing lipid rafts, C282Y-HFE was not 
Table 1 | Comparison of in vivo and in vitro findings of H63D- and C282Y-HFE variants.

\begin{tabular}{|c|c|c|c|}
\hline & H63D & C282Y & \\
\hline Iron & $\uparrow$ & $\uparrow$ & Lee etal. (2007) \\
\hline Oxidative stress & $\uparrow$ & $\uparrow$ & Lee et al. (2007) \\
\hline Cellular location & Plasma membrane & $\begin{array}{l}\text { Endoplasmic } \\
\text { reticulum/golgi }\end{array}$ & Feder et al. (1997) \\
\hline Cellular cholesterol & $\downarrow \downarrow$ & $\uparrow \uparrow$ & Ali-Rahmani et al. (2014a,b) \\
\hline GM1 & $\uparrow \uparrow$ & $\downarrow \downarrow$ & Ali-Rahmani et al. (2011) \\
\hline Lipid raft & Yes & No & Ali-Rahmani et al. (2011) \\
\hline Cellular phenotype & $\begin{array}{l}\downarrow \text { Cell proliferation } \\
\text { apoptotic }\end{array}$ & $\uparrow$ Cell proliferation & Lee et al. (2007), Ali-Rahmani etal. (2011), Liu etal. (2011) \\
\hline Disease risk & $A D$ & $\begin{array}{l}\text { Cancer; } \\
\text { protective for AD }\end{array}$ & $\begin{array}{l}\text { Moalem etal. (2000), Sampietro etal. (2001), Combarros } \\
\text { et al. (2003), Pulliam et al. (2003), Connor and Lee (2006), } \\
\text { Liu etal. (2013) }\end{array}$ \\
\hline
\end{tabular}

(Ali-Rahmani et al., 2011). Because lipid rafts provide a platform for a number of cell signaling pathways, an intriguing possibility is that expression of C282Y-HFE alters at least some cell signaling thereby disrupting normal homeostasis. Here it is important to note that although H63D-HFE is present in lipid rafts, its interaction with TfR is altered such that it loses the ability to prevent $\mathrm{Tf}$ binding to TfR and iron uptake. Therefore, interactions of both of these mutants with other proteins may be affected. Currently, other binding partners of WT and mutant HFE proteins are not known and should be interrogated in order to elucidate its role in cell signaling. In response to the question of whether the variant itself is a culprit, current evidence indicates that the variant per se as well as the resulting iron overload contribute to the observed effects.

Another potential area for future investigation is to identify proteins that act as molecular switches in the cell and whose expression and/or activity are directly regulated by cellular iron content. This would help to dissect the molecular mechanism(s) underlying a wide array of processes and diseases such as AD and cancer in which iron is implicated. One possible candidate is peptidylprolyl cis-trans isomerase (Pin1). It is known to play a key role in regulation of signal transduction pathways (Wulf et al., 2005), particularly in cell proliferation (Lu et al., 1996). Phosphorylation of Pin 1 causes it to become inactive. Pin 1 modulates the folding, activity, and stability of target proteins by causing their isomerization. The findings that Pin 1 is downregulated in degenerating neurons from AD patients (Liou et al., 2003) but its expression and activity is elevated in many cancers including those of the breast, prostate, brain, lung, and colon (Ryo et al., 2001; Wulf et al., 2001; Ayala et al., 2003; Bao et al., 2004), provides support for the argument that Pin 1 can serve as a molecular switch. Interestingly, varying concentrations of iron were shown to alter Pin1 phosphorylation and activity in WT- and H63D-HFE cells, indicating that iron can modulate Pin1 activity, but the change in expression is HFE genotype dependent (Hall et al., 2010); presenting another example were HFE genotype could impact cellular basis of disease.

\section{THERAPEUTIC IMPLICATIONS: IS STATIN THERAPY APPROPRIATE FOR PATIENTS WITH AD AND THE HFE-H63D GENE VARIANT?}

Because $\mathrm{AD}$ is a multifactorial disease with evidence for the involvement of environmental factors, multiple pathways and genetic mutations in genes with diverse functions, it would be beneficial to identify subpopulations responsive to specific treatments based on their genotype. Identification of genetic and environmental factors, knowledge about their interactions, and resulting pathological markers should allow us to improve therapeutic outcomes. The studies described regarding the effects of a mutation affecting iron uptake on cholesterol metabolism and their relationship to neurodegeneration support our position that eventually medical interventions must take HFE genotype into consideration. For example, the observation that cells carrying the H63D-HFE allele have lower baseline levels of total cholesterol and exhibit slower growth relative to those expressing WT-HFE (Ali-Rahmani et al., 2014a) supports the idea that H63D-HFE positive patients with $\mathrm{AD}$ will differ from those with WT-HFE in their response to statin therapy. Our findings that treatment of H63D-HFE cells with a statin that can cross the BBB resulted in decreased cell survival and that statin treatment of the ALS mouse model that also carries the HFE-H63D gene variant worsens the disease (unpublished data) supports this proposal. These data imply that lowering CNS cholesterol could be deleterious to neuronal function, and more so in the carriers of H63D-HFE. Further support for this proposal is provided by a recent clinical trial that showed a reduction in right hippocampal volume after 1 year of atorvastatin therapy in $\mathrm{AD}$ patients (Sparks et al., 2008). Though in this study they didn't stratify based on HFE genotype, such an investigation will be valuable. This finding suggests that in addition to lowering plasma cholesterol levels in AD patients, statin treatment may have reduced brain cholesterol possibly resulting in neuronal loss and atrophy of certain brain regions. Thus, our data are suggesting that use of statins that can cross the $\mathrm{BBB}$, particularly in the presence of HFE gene variants should be evaluated clinically.

In conclusion, the research discussed points out a connection between iron, cholesterol, and neuronal function. This review also 
provides a synopsis of some of the many questions about the roles that iron, cholesterol, and sphingolipids may have in the evolution of dementing diseases in the brain and introduces a new concept, namely that HFE gene variants dramatically influence cholesterol metabolism.

\section{REFERENCES}

Abad-Rodriguez, J., Ledesma, M. D., Craessaerts, K., Perga, S., Medina, M., Delacourte, A., et al. (2004). Neuronal membrane cholesterol loss enhances amyloid peptide generation. J. Cell Biol. 167, 953-960. doi: 10.1083/jcb. 200404149

Adams, P. C., Reboussin, D. M., Barton, J. C., Mclaren, C. E., Eckfeldt, J. H., Mclaren G. D., et al. (2005). Hemochromatosis and iron-overload screening in a racially diverse population. N. Engl. J. Med. 352, 1769-1778. doi: 10.1056/NEJMoa041534

Albert, S. M. (2008). Dyslipidemia in ALS - Good, bad, or unclear? Neurology 70 , 988-989. doi: 10.1212/01.wnl.0000306636.61882.42

Ali-Rahmani, F., Grigson, P. S., Lee, S., Neely, E., Connor, J. R., and Schengrund, C. L. (2014a). H63D mutation in hemochromatosis alters cholesterol metabolism and induces memory impairment. Neurobiol. Aging 35, 1511.e1-1511.e112. doi: 10.1016/j.neurobiolaging.2013.12.014

Ali-Rahmani, F., Huang, M. A., Schengrund, C. L., Connor, J. R., and Lee, S. Y. (2014b). C282Y-HFE gene variant affects cholesterol metabolism in human neuroblastoma cells. PLoS ONE 9:e88724. doi: 10.1371/journal.pone.0088724

Ali-Rahmani, F., Hengst, J. A., Connor, J. R., and Schengrund, C. L. (2011). Effect of HFE variants on sphingolipid expression by SH-SY5Y human neuroblastoma cells. Neurochem. Res. 36, 1687-1689. doi: 10.1007/s11064-011-0403-8

Ariga, T., Kobayashi, K., Hasegawa, A., Kiso, M., Ishida, H., and Miyatake, T. (2001). Characterization of high-affinity binding between gangliosides and amyloid $\beta$ protein. Arch. Biochem. Biophys. 388, 225-230. doi: 10.1006/abbi.2001.2304

Atzmon, G., Gabriely, I., Greiner, W., Davidson, D., Schechter, C., and Barzilai, N. (2002). Plasma HDL levels highly correlate with cognitive function in exceptional longevity. J. Gerontol. A Biol. Sci. Med. Sci. 57, M712-M715. doi: 10.1093/gerona/57.11.M712

Ayala, G., Wang, D. G., Wulf, G., Frolov, A., Li, R., Sowadski, J., et al. (2003). The prolyl isomerase Pinl is a novel prognostic marker in human prostate cancer. Cancer Res. 63, 6244-6251.

Bao, L., Kimzey, A., Sauter, G., Sowadski, J. M., Lu, K. P., and Wang, D. G. (2004). Prevalent overexpression of prolyl isomerase Pin 1 in human cancers. Am. J. Pathol. 164, 1727-1737. doi: 10.1016/S0002-9440(10)63731-5

Barenholz, Y. (2002). Cholesterol and other membrane active sterols: from membrane evolution to "rafts." Prog. Lipid Res. 41, 1-5. doi: 10.1016/S0163-7827(01) 00016-9

Bartzokis, G. (2009). Alzheimer's disease as homeostatic responses to agerelated myelin breakdown. Neurobiol. Aging 32, 1341-1371. doi: 10.1016/j. neurobiolaging.2009.08.007

Bartzokis, G. (2011). Alzheimer's disease as homeostatic responses to agerelated myelin breakdown. Neurobiol. Aging 32, 1341-1371. doi: 10.1016/ j.neurobiolaging.2009.08.007

Bartzokis, G., Cummings, J. L., Markham, C. H., Marmarelis, P. Z., Treciokas, L. J., Tishler, T. A., et al. (1999). MRI evaluation of brain iron in earlier- and later-onset Parkinson's disease and normal subjects. Magn. Reson. Imaging 17, 213-222. doi: 10.1016/S0730-725X(98)00155-6

Bartzokis, G., Lu, P. H., Tishler, T. A., Peters, D. G., Kosenko, A., Barrall, K. A., et al. (2010). Prevalent iron metabolism gene variants associated with increased brain ferritin iron in healthy older men. J. Alzheimers Dis. 20, 333-341. doi: 10.3233/JAD-2010-1368

Bartzokis, G., Mintz, J., Sultzer, D., Marx, P., Herzberg, J. S., Phelan, C. K., et al. (1994). In vivo MR evaluation of age-related increases in brain iron. AJNR Am. J. Neuroradiol. 15, 1129-1138.

Bartzokis, G., Sultzer, D., Cummings, J., Holt, L. E., Hance, D. B., Henderson, V. W., et al. (2000). In vivo evaluation of brain iron in Alzheimer disease using magnetic resonance imaging. Arch. Gen. Psychiatry 57, 47-53. doi: 10.1001/archpsyc.57.1.47

Bartzokis, G., Tishler, T. A., Lu, P. H., Villablanca, P., Altshuler, L. L., Carter, M., et al. (2007). Brain ferritin iron may influence age- and gender-related risks of neurodegeneration. Neurobiol. Aging 28, 414-423. doi: 10.1016/j.neurobiolaging. 2006.02.005
Berg, D., Hoggenmuller, U., Hofmann, E., Fischer, R., Kraus, M., Scheurlen, M., et al. (2000). The basal ganglia in haemochromatosis. Neuroradiology 42, 9-13. doi: $10.1007 / \mathrm{s} 002340050002$

Bertram, L., Mcqueen, M. B., Mullin, K., Blacker, D., and Tanzi, R. E. (2007). Systematic meta-analyses of Alzheimer disease genetic association studies: the AlzGene database. Nat. Genet. 39, 17-23. doi: 10.1038/ng1934

Besshoh, S., Chen, S., Brown, I. R., and Gurd, J. W. (2007). Developmental changes in the association of NMDA receptors with lipid rafts. J. Neurosci. Res. 85, 18761883. doi: 10.1002/Jnr.21336

Bjorkhem, I., and Meaney, S. (2004). Brain cholesterol: long secret life behind a barrier. Arterioscler. Thromb. Vasc. Biol. 24, 806-815. doi: 10.1161/01.Atv. $0000120374.59826 .1 \mathrm{~b}$

Bjorkhem, I., Lutjohann, D., Breuer, O., Sakinis, A., and Wennmalm, A. (1997). Importance of a novel oxidative mechanism for elimination of brain cholesterol Turnover of cholesterol and 24(S)-hydroxycholesterol in rat brain as measured with ${ }^{18} \mathrm{O}_{2}$ techniques in vivo and in vitro. J. Biol. Chem. 272, 30178-30184. doi: $10.1074 /$ jbc. 272.48 .30178

Bjorkhem, I., Lutjohann, D., Diczfalusy, U., Stahle, L., Ahlborg, G., and Wahren, J. (1998). Cholesterol homeostasis in human brain: turnover of 24Shydroxycholesterol and evidence for a cerebral origin of most of this oxysterol in the circulation. J. Lipid Res. 39, 1594-1600.

Bodovitz, S., Falduto, M. T., Frail, D. E., and Klein, W. L. (1995). Iron levels modulate $\alpha$-secretase cleavage of amyloid precursor protein. J. Neurochem. 64, 307-315. doi: 10.1046/j.1471-4159.1995.64010307.x

Bogdanovic, N., Corder, E., Lannfelt, L., and Winblad, B. (2002). APOE polymorphism and clinical duration determine regional neuropathology in Swedish $\operatorname{APP}(670,671)$ mutation carriers: implications for late-onset Alzheimer's disease. J. Cell. Mol. Med. 6, 199-214. doi: 10.1111/j.1582-4934.2002.tb00187.x

Bouillot, C., Prochiantz, A., Rougon, G., and Allinquant, B. (1996). Axonal amyloid precursor protein expressed by neurons in vitro is present in a membrane fraction with caveolae-like properties. J. Biol. Chem. 271, 7640-7644. doi: 10.1074/jbc.271.13.7640

Boyles, J. K., Pitas, R. E., Wilson, E., Mahley, R. W., and Taylor, J. M. (1985). Apolipoprotein-E associated with astrocytic glia of the central nervous-system and with nonmyelinating glia of the peripheral nervous-system. J. Clin. Invest. 76, 1501-1513. doi: 10.1172/JCI112130

Bretillon, L., Lutjohann, D., Stahle, L., Widhe, T., Bindl, L., Eggertsen, G., et al. (2000a). Plasma levels of 24S-hydroxycholesterol reflect the balance between cerebral production and hepatic metabolism and are inversely related to body surface. J. Lipid Res. 41, 840-845.

Bretillon, L., Siden, A., Wahlund, L. O., Lutjohann, D., Minthon, L., Crisby, M., et al. (2000b). Plasma levels of 24S-hydroxycholesterol in patients with neurological diseases. Neurosci. Lett. 293, 87-90. doi: 10.1016/S0304-3940(00)01466-X

Britton, R. S., Bacon, B. R., and Recknagel, R. O. (1987). Lipid-Peroxidation and Associated hepatic organelle dysfunction in iron overload. Chem. Phys. Lipids 45, 207-239. doi: 10.1016/0009-3084(87)90066-1

Brunet, S., Guertin, F., Thibault, L., Gavino, V., Delvin, E., and Levy, E. (1997). Iron-salicylate complex induces peroxidation, alters hepatic lipid profile and affects plasma lipoprotein composition. Atherosclerosis 129, 159-168. doi: 10.1016/S0021-9150(96)06010-8

Brunet, S., Thibault, L., Delvin, E., Yotov, W., Bendayan, M., and Levy, E. (1999). Dietary iron overload and induced lipid peroxidation are associated with impaired plasma lipid transport and hepatic sterol metabolism in rats. Hepatology 29, 1809-1817. doi: 10.1002/hep.510290612

Brys, M., Pirraglia, E., Rich, K., Rolstad, S., Mosconi, L., Switalski, R., et al. (2009). Prediction and longitudinal study of CSF biomarkers in mild cognitive impairment. Neurobiol. Aging 30, 682-690. doi: 10.1016/j.neurobiolaging.2007.08.010

Buchanan, D. D., Silburn, P. A., Chalk, J. B., Le Couteur, D. G., and Mellick, G. D. (2002). The Cys282Tyr polymorphism in the HFE gene in Australian Parkinson's disease patients. Neurosci. Lett. 327, 91-94. doi: 10.1016/S0304-3940(02)00398-1

Bush, A. I. (2003). The metallobiology of Alzheimer's disease. Trends Neurosci. 26, 207-214. doi: 10.1016/S0166-2236(03)00067-5

Cai, Z. Y., Zhao, B., and Ratka, A. (2011). Oxidative Stress and $\beta$-Amyloid Protein in Alzheimer's disease. Neuromolecular Med. 13, 223-250. doi: 10.1007/s12017011-8155-9

Cam, J. A., and Bu, G. (2006). Modulation of $\beta$-amyloid precursor protein trafficking and processing by the low density lipoprotein receptor family. Mol. Neurodegener. 1,8. doi: 10.1186/1750-1326-1-8 
Camaschella, C., Roetto, A., and De Gobbi, M. (2002). Genetic haemochromatosis: genes and mutations associated with iron loading. Best Pract. Res. Clin. Haematol. 15, 261-276. doi: 10.1053/beha.2002.0207

Cardoso, C. S., and de Sousa, M. (2003). HFE, the MHC and hemochromatosis: paradigm for an extended function for MHC class I. Tissue Antigens 61, 263-275. doi: 10.1034/j.1399-0039.2003.00065.x

Carlini, R. G., Alonzo, E., Bellorin-Font, E., and Weisinger, J. R. (2006). Apoptotic stress pathway activation mediated by iron on endothelial cells in vitro. Nephrol. Dial. Transplant. 21, 3055-3061. doi: 10.1093/Ndt/Gfl341

Cartagena, C. M., Burns, M. P., and Rebeck, G. W. (2010). 24S-hydroxycholesterol effects on lipid metabolism genes are modeled in traumatic brain injury. Brain Res. 1319, 1-12. doi: 10.1016/j.brainres.2009.12.080

Castellani, R. J., Moreira, P. I., Liu, G., Dobson, J., Perry, G., Smith, M. A., et al. (2007). Iron: the redox-active center of oxidative stress in Alzheimer disease. Neurochem. Res. 32, 1640-1645. doi: 10.1007/s11064-007-9360-7

Castellani, R. J., Moreira, P. I., Perry, G., and Zhu, X. W. (2012). The role of iron as a mediator of oxidative stress in Alzheimer disease. Biofactors 38, 133-138. doi 10.1002/Biof.1010

Cedazo-Minguez, A., and Cowburn, R. F. (2001). Apolipoprotein E: a major piece in the Alzheimer's disease puzzle. J. Cell. Mol. Med. 5, 254-266. doi: 10.1111/j.15824934.2001.tb00159.x

Chenais, B., Morjani, H., and Drapier, J. C. (2002). Impact of endogenous nitric oxide on microglial cell energy metabolism and labile iron pool. J. Neurochem. 81, 615-623. doi: 10.1046/j.1471-4159.2002.00864.x

Cheng, H., Xu, J., Mckeel, D. W., and Han, X. (2003). Specificity and potential mechanism of sulfatide deficiency in Alzheimer's disease: an electrospray ionization mass spectrometric study. Cell. Mol. Biol. 49, 809-818.

Chio, A., Calvo, A., Ilardi, A., Cavallo, E., Moglia, C., Mutani, R., et al. (2009). Lower serum lipid levels are related to respiratory impairment in patients with ALS. Neurology 73, 1681-1685. doi: 10.1212/Wnl.0b013e3181cldf1e

Choo-Smith, L. P., Garzon-Rodriguez, W., Glabe, C. G., and Surewicz, W. K. (1997) Acceleration of amyloid fibril formation by specific binding of $A \beta-(1-40)$ peptide to ganglioside-containing membrane vesicles. J. Biol. Chem. 272, 22987-22990. doi: $10.1074 /$ jbc.272.37.22987

Colognato, H., Baron, W., Avellana-Adalid, V., Relvas, J. B., Baron-Van Evercooren, A., Georges-Labouesse, E., et al. (2002). CNS integrins switch growth factor signalling to promote target-dependent survival. Nat. Cell Biol. 4, 833-841. doi: $10.1038 / \mathrm{Ncb} 865$

Combarros, O., Garcia-Roman, M., Fontalba, A., Fernandez-Luna, J. L., Llorca, J., Infante, J., et al. (2003). Interaction of the H63D mutation in the hemochromatosis gene with the apolipoprotein $\mathrm{E}$ epsilon 4 allele modulates age at onset of Alzheimer's disease. Dement. Geriatr. Cogn. Disord. 15, 151-154. doi: $10.1159 / 000068480$

Connor, J. R., and Lee, S. Y. (2006). HFE mutations and Alzheimer's disease. J. Alzheimers Dis. 10, 267-276.

Connor, J. R., Menzies, S. L., Burdo, J. R., and Boyer, P. J. (2001). Iron and iron management proteins in neurobiology. Pediatr. Neurol. 25, 118-129. doi: 10.1016/S0887-8994(01)00303-4

Connor, J. R., Menzies, S. L., St Martin, S. M., and Mufson, E. J. (1992a). A histochemical study of iron, transferrin, and ferritin in Alzheimer's diseased brains. $J$. Neurosci. Res. 31, 75-83. doi: 10.1002/jnr.490310111

Connor, J. R., Snyder, B. S., Beard, J. L., Fine, R. E., and Mufson, E. J. (1992b). Regional distribution of iron and iron-regulatory proteins in the brain in aging and Alzheimer's disease. J. Neurosci. Res. 31, 327-335. doi: 10.1002/jnr.490310214

Connor, J. R., Snyder, B. S., Arosio, P., Loeffler, D. A., and Lewitt, P. (1995). A Quantitative-analysis of isoferritins in select regions of aged, parkinsonian, and, Alzheimers Diseased Brains. J. Neurochem. 65, 717-724. doi: 10.1046/j.14714159.1995.65020717.x

Corder, E. H. (1993). Gene dose of apolipoprotein E type 4 allele and the risk of Alzheimer's disease in late onset families. Science 261, 921-923. doi: $10.1126 /$ science. 8346443

Correia, A. P., Pinto, J. P., Dias, V., Mascarenhas, C., Almeida, S., and Porto, G. (2009). CAT53 and HFE alleles in Alzheimer's disease: A putative protective role of the C282Y HFE mutation. Neurosci. Lett. 457, 129-132. doi: 10.1016/j.neulet.2009.03.088

Costantini, C., Weindruch, R., Della Valle, G., and Puglielli, L. (2005). TrkA-top75(NTR) molecular switch activates amyloid $\beta$-peptide generation during aging. Biochem. J. 391, 59-67. doi: 10.1042/Bj20050700
Cutler, R. G., Kelly, J., Storie, K., Pedersen, W. A., Tammara, A., Hatanpaa, K., et al (2004). Involvement of oxidative stress-induced abnormalities in ceramide and cholesterol metabolism in brain aging and Alzheimer's disease. Proc. Natl. Acad. Sci. U.S.A. 101, 2070-2075. doi: 10.1073/pnas.0305799101 0305799101

Dabbagh, A. J., Mannion, T., Lynch, S. M., and Frei, B. (1994). The effect of iron overload on rat plasma and liver oxidant status in vivo. Biochem. J. 300, 799-803.

Dabbagh, A. J., Shwaery, G. T., Keaney, J. F., and Frei, B. (1997). Effect of iron overload and iron deficiency on atherosclerosis in the hypercholesterolemic rabbit. Arterioscler. Thromb. Vasc. Biol. 17, 2638-2645. doi: 10.1161/01.ATV.17. 11.2638

De La Cruz, J. P., Quintero, L., Villalobos, M. A., and Sanchez de la Cuesta, F. (2000). Lipid peroxidation and glutathione system in hyperlipemic rabbits: influence of olive oil administration. Biochim. Biophys. Acta 1485, 36-44. doi: 10.1016/S13881981(00)00027-5

Debruin, L. S., and Harauz, G. (2007). White matter rafting - membrane microdomains in myelin. Neurochem. Res. 32, 213-228. doi: 10.1007/s11064006-9137-4

Dehouck, B., Dehouck, M. P., Fruchart, J. C., and Cecchelli, R. (1994). Upregulation of the low density lipoprotein receptor at the blood-brain barrier: intercommunications between brain capillary endothelial cells and astrocytes. J. Cell Biol. 126, 465-473. doi: 10.1083/jcb.126.2.465

Dehouck, B., Fenart, L., Dehouck, M. P., Pierce, A., Torpier, G., and Cecchelli, R. (1997). A new function for the LDL receptor: transcytosis of LDL across the blood-brain barrier. J. Cell Biol. 138, 877-889. doi: 10.1083/jcb.138.4.877

Dietschy, J. M., and Turley, S. D. (2001). Cholesterol metabolism in the brain. Curr Opin. Lipidol. 12, 105-112. doi: 10.1097/00041433-200104000-00003

Ding, B., Chen, K. M., Ling, H. W., Sun, F., Li, X., Wan, T., et al. (2009). Correlation of iron in the hippocampus with MMSE in patients with Alzheimer's disease. $J$. Magn. Reson. Imaging 29, 793-798. doi: 10.1002/Jmri.21730

Dolev, I., and Michaelson, D. M. (2004). A nontransgenic mouse model shows inducible amyloid- $\beta$ (A $\beta$ ) peptide deposition and elucidates the role of apolipoprotein E in the amyloid cascade. Proc. Natl. Acad. Sci. U.S.A. 101, 13909-13914. doi: 10.1073/pnas.0404458101

Drakesmith, H., Sweetland, E., Schimanski, L., Edwards, J., Cowley, D., Ashraf, M., et al. (2002). The hemochromatosis protein HFE inhibits iron export from macrophages. Proc. Natl. Acad. Sci. U.S.A. 99, 15602-15607. doi: 10.1073/pnas.242614699

Du, G. W., Lewis, M. M., Shaffer, M. L., Chen, H. L., Yang, Q. X., Mailman, R. B., et al. (2012). Serum cholesterol and nigrostriatal R2* values in Parkinson's disease. PLoS ONE 7:e35397. doi: 10.1371/journal.pone.0035397

Ellervik, C., Tybjaerg-Hansen, A., Appleyard, M., Sillesen, H., Boysen, G., and Nordestgaard, B. G. (2007). Hereditary hemochromatosis genotypes and risk of ischemic stroke. Neurology 68, 1025-1031. doi: 10.1212/01.wnl. 0000257814.77115.d6

Fazio, S., Linton, M. F., and Swift, L. L. (2000). The cell biology and physiologic relevance of ApoE recycling. Trends Cardiovasc. Med. 10, 23-30. doi: 10.1016/S1050-1738(00)00033-5

Feder, J. N., Penny, D. M., Irrinki, A., Lee, V. K., Lebrón, J. A., Watson, N., et al. (1998) The hemochromatosis gene product complexes with the transferrin receptor and lowers its affinity for ligand binding. Proc. Natl. Acad. Sci. U.S.A. 95, 1472-1477. doi: 10.1073/pnas.95.4.1472

Feder, J. N., Tsuchihashi, Z., Irrinki, A., Lee, V. K., Mapa, F. A., Morikang, E., et al. (1997). The hemochromatosis founder mutation in HLA-H disrupts $\beta_{2}$ microglobulin interaction and cell surface expression. J. Biol. Chem. 272, 1402514028. doi: 10.1074/jbc.272.22.14025

Ferrari, C. K. B. (2000). Free radicals, lipid peroxidation and antioxidants in apoptosis: implications in cancer, cardiovascular and neurological diseases. Biologia 55, 581-590.

Fleming, R. E., Migas, M. C., Holden, C. C., Waheed, A., Britton, R. S., Tomatsu, S., et al. (2000). Transferrin receptor 2: continued expression in mouse liver in the face of iron overload and in hereditary hemochromatosis. Proc. Natl. Acad. Sci. U.S.A. 97, 2214-2219. doi: 10.1073/pnas.040548097

Gannon, P. O., Medelci, S., Le Page, C., Beaulieu, M., Provencher, D. M., MesMasson, A. M., et al. (2011). Impact of hemochromatosis gene (HFE) mutations on epithelial ovarian cancer risk and prognosis. Int. J. Cancer 128, 2326-2334. doi: 10.1002/ijc. 25577

Ghribi, O., Golovko, M. Y., Larsen, B., Schrag, M., and Murphy, E. J. (2006). Deposition of iron and $\beta$-amyloid plaques is associated with cortical cellular 
damage in rabbits fed with long-term cholesterol-enriched diets. J. Neurochem. 99, 438-449. doi: 10.1111/j.1471-4159.2006.04079.x

Gielen, E., Baron, W., Vandeven, M., Steels, P., Hoekstra, D., and Ameloot, M. (2006). Rafts in oligodendrocytes: evidence and structure-function relationship. Glia 54, 499-512. doi: 10.1002/Glia.20406

Ginsberg, L., Atack, J. R., Rapoport, S. I., and Gershfeld, N. L. (1993a). Evidence for a membrane lipid defect in Alzheimer disease. Mol. Chem. Neuropathol. 19, 37-46. doi: 10.1007/BF03160167

Ginsberg, L., Atack, J. R., Rapoport, S. I., and Gershfeld, N. L. (1993b). Regional specificity of membrane instability in Alzheimer's disease brain. Brain Res. 615, 355-357. doi: 10.1016/0006-8993(93)90050-W

Gokkusu, C., and Mostafazadeh, T. (2003). Changes of oxidative stress in various tissues by long-term administration of vitamin $\mathrm{E}$ in hypercholesterolemic rats. Clin. Chim. Acta 328, 155-161. doi: 10.1016/S0009-8981(02)00388-1

Gong, J. S. (2002). Apolipoprotein E (ApoE) isoform-dependent lipid release from astrocytes prepared from human ApoE3 and ApoE4 knock-in mice. J. Biol. Chem. 277, 29919-29926. doi: 10.1074/jbc.M203934200

Goodall, E. F., Greenway, M. J., Van Marion, I., Carroll, C. B., Hardiman, O., and Morrison, K. E. (2005). Association of the H63D polymorphism in the hemochromatosis gene with sporadic ALS. Neurology 65, 934-937. doi: 10.1212/01.wnl.0000176032.94434.d4

Gottfries, C. G., Karlsson, I., and Svennerholm, L. (1996). Membrane components separate early-onset Alzheimer's disease from senile dementia of the Alzheimer type. Int. Psychogeriatr. 8, 365-372. doi: 10.1017/S1041610296002736

Grimm, M. O. W., Rothhaar, T. L., and Hartmann, T. (2012). The role of APP proteolytic processing in lipid metabolism. Exp. Brain Res. 217, 365-375. doi 10.1007/s00221-011-2975-6

Hall, E. C., Lee, S. Y., Mairuae, N., Simmons, Z., and Connor, J. R. (2011) Expression of the HFE allelic variant H63D in SH-SY5Y cells affects tau phosphorylation at serine residues. Neurobiol. Aging 32, 1409-1419. doi: 10.1016/j.neurobiolaging.2009.08.012

Hall, E. C. II, Lee, S. Y., Simmons, Z., Neely, E. B., Nandar, W., and Connor, J. R. (2010). Prolyl-peptidyl isomerase, Pin1, phosphorylation is compromised in association with the expression of the HFE polymorphic allele, H63D. Biochim. Biophys. Acta 1802, 389-395. doi: 10.1016/j.bbadis.2010.01.004

Hallgren, B., and Sourander, P. (1958). The effect of age on the non-haemin iron in the human brain. J. Neurochem. 3, 41-51. doi: 10.1111/j.14714159.1958.tb12607.x

Han, X. L., Holtzman, D. M., Mckeel, D. W., Kelley, J., and Morris, J. C. (2002). Substantial sulfatide deficiency and ceramide elevation in very early Alzheimer's disease: potential role in disease pathogenesis. J. Neurochem. 82, 809-818. doi: 10.1046/j.1471-4159.2002.00997.x

Hannun, Y. A., and Obeid, L. M. (2002). The ceramide-centric universe of lipidmediated cell regulation: stress encounters of the lipid kind. J. Biol. Chem. 277 25847-25850. doi: 10.1074/jbc.R200008200

Haughey, N. J., Bandaru, V. V. R., Bae, M., and Mattson, M. P. (2010). Roles for dysfunctional sphingolipid metabolism in Alzheimer's disease neuropathogenesis. Biochim. Biophys. Acta 1801, 878-886. doi: 10.1016/j.bbalip.2010.05.003

Hayashi, H., Kimura, N., Yamaguchi, H., Hasegawa, K., Yokoseki, T., Shibata, M., et al. (2004). A seed for Alzheimer amyloid in the brain. J. Neurosci. 24, 4894-4902. doi: 10.1523/Jneurosci.0861-04.2004

Hayashi, H., Mizuno, T., Michikawa, M., Haass, C., and Yanagisawa, K. (2000). Amyloid precursor protein in unique cholesterol-rich microdomains different from caveolae-like domains. Biochim. Biophys. Acta 1483, 81-90. doi: 10.1016/S1388-1981(99)00174-2

He, X. X., Huang, Y., Li, B., Gong, C. X., and Schuchman, E. H. (2010). Deregulation of sphingolipid metabolism in Alzheimer's disease. Neurobiol. Aging 31, 398-408. doi: 10.1016/j.neurobiolaging.2008.05.010

Hebert, L. E., Weuve, J., Scherr, P. A., and Evans, D. A. (2013). Alzheimer disease in the United States (2010-2050) estimated using the 2010 census. Neurology 80 , 1778-1783. doi: 10.1212/WNL.0b013e31828726f5

Herz, J. (1988). Surface location and high affinity for calcium of a 500-kd liver membrane protein closely related to the LDL-receptor suggest a physiological role as lipoprotein receptor. EMBO J. 7, 4119-4127.

Heverin, M., Bogdanovic, N., Lutjohann, D., Bayer, T., Pikuleva, I., Bretillon, L., et al. (2004). Changes in the levels of cerebral and extracerebral sterols in the brain of patients with Alzheimer's disease. J. Lipid Res. 45, 186-193. doi: 10.1194/jlr.M300320-JLR200
Hidalgo, C., and Nunez, M. T. (2007). Calcium, iron and neuronal function. IUBMB Life 59, 280-285. doi: 10.1080/15216540701222906

Hirose, W., Ikematsu, K., and Tsuda, R. (2003). Age-associated increases in heme oxygenase-1 and ferritin immunoreactivity in the autopsied brain. Leg. Med. (Tokyo) 5(Suppl. 1), S360-S366. doi: 10.1016/S1344-6223(02)00133-5

Hirsch, E. C., and Faucheux, B. A. (1998). Iron metabolism and Parkinson's disease. Mov. Disord. 13, 39-45.

Holtzman, D. M., Pitas, R. E., Kilbridge, J., Nathan, B., Mahley, R. W., Bu, G., et al. (1995). Low density lipoprotein receptor-related protein mediates apolipoprotein E-dependent neurite outgrowth in a central nervous system-derived neuronal cell line. Proc. Natl. Acad. Sci. U.S.A. 92, 9480-9484. doi: 10.1073/pnas.92.21.9480

Honda, K., Casadesus, G., Petersen, R. B., Perry, G., and Smith, M. A. (2004) Oxidative stress and redox-active iron in Alzheimer's disease. Ann. N. Y. Acad. Sci. 1012, 179-182. doi: 10.1196/annals.1306.015

Huang, P., Xu, W., Yoon, S. I., Chen, C. G., Chong, P. L. G., and Liu-Chen, L. Y. (2007). Cholesterol reduction by methyl- $\beta$-cyclodextrin attenuates the delta opioid receptor-mediated signaling in neuronal cells but enhances it in nonneuronal cells. Biochem. Pharmacol. 73, 534-549. doi: 10.1016/j.bcp.2006.10.032

Igbavboa, U., Avdulov, N. A., Schroeder, F., and Wood, W. G. (1996). Increasing age alters transbilayer fluidity and cholesterol asymmetry in synaptic plasma membranes of mice. J. Neurochem. 66, 1717-1725. doi: 10.1046/j.14714159.1996.66041717.x

Igbavboa, U., Eckert, G. P., Malo, T. M., Studniski, A. E., Johnson, L. N. A., Yamamoto, N., et al. (2005). Murine synaptosomal lipid raft protein and lipid composition are altered by expression of human apoE 3 and 4 and by increasing age. J. Neurol. Sci. 229, 225-232. doi: 10.1016/j.jns.2004.11.037

Jarvik, G. P., Wijsman, E. M., Kukull, W. A., Schellenberg, G. D., Yu, C., and Larson, E. B. (1995). Interactions of apolipoprotein E genotype, total cholesterol level, age, and sex in prediction of Alzheimer's disease: a case-control study. Neurology 45, 1092-1096. doi: 10.1212/WNL.45.6.1092

Jeon, H., and Blacklow, S. C. (2005). Structure and physiologic function of the low-density lipoprotein receptor. Annu. Rev. Biochem. 74, 535-562. doi: 10.1146/annurev.biochem.74.082803.133354

Jira, P. E., Waterham, H. R., Wanders, R. J. A., Smeitink, J. A. M., Sengers, R. C. A., and Wevers, R. A. (2003). Smith-Lemli-Opitz syndrome and the DHCR7 gene. Ann. Hum. Genet. 67, 269-280. doi: 10.1046/j.1469-1809.2003.00034.x

Jurevics, H., and Morell, P. (1995). Cholesterol for synthesis of myelin is made locally, not imported into brain. J. Neurochem. 64, 895-901. doi: 10.1046/j.14714159.1995.64020895.x

Jurevics, H., and Morell, P. (1997). Sources of cholesterol during development of the rat fetus and fetal organs. J. Neurochem. 69, S15-S15.

Kauwe, J. S. K., Bertelsen, S., Mayo, K., Cruchaga, C., Abraham, R., Hollingworth, P., et al. (2010). Suggestive synergy between genetic variants in TF and HFE as risk factors for Alzheimer's disease. Am. J. Med. Genet. B Neuropsychiatr. Genet. 153B, 955-959. doi: 10.1002/Ajmg.B.31053

Kehrer, J. P. (1993). Free-radicals as mediators of tissue-injury and disease. Crit. Rev. Toxicol. 23, 21-48. doi: 10.3109/10408449309104073

Keller, R. K., Arnold, T. P., and Fliesler, S. J. (2004). Formation of 7dehydrocholesterol-containing membrane rafts in vitro and in vivo, with relevance to the Smith-Lemli-Opitz syndrome. J. Lipid Res. 45, 347-355. doi: 10.1194/jlr.M300232-JLR200

Kessel, A., Ben-Tal, N., and May, S. (2001). Interactions of cholesterol with lipid bilayers: the preferred configuration and fluctuations. Biophys. J. 81, 643-658. doi: 10.1016/S0006-3495(01)75729-3

Kim, J. M., Stewart, R., Shin, I. S., and Yoon, J. S. (2002). Low cholesterol, cognitive function and Alzheimer s disease in a community population with cognitive impairment. J. Nutr. Health Aging 6, 320-323.

Kimura, N., and Yanagisawa, K. (2007). Endosomal accumulation of GM1 ganglioside-bound amyloid $\beta$-protein in neurons of aged monkey brains Neuroreport 18, 1669-1673. doi: 10.1097/WNR.0b013e3282f0d2ab

Kispal, G., Sipos, K., Lange, H., Fekete, Z., Bedekovics, T., Janaky, T., et al. (2005). Biogenesis of cytosolic ribosomes requires the essential iron-sulphur protein Rlilp and mitochondria. EMBO J. 24, 589-598. doi: 10.1038/sj.emboj.7600541

Kolesnick, R. N., and Kronke, M. (1998). Regulation of ceramide production and apoptosis. Annu. Rev. Physiol. 60, 643-665. doi: 10.1146/annurev.physiol.60.1.643 Kuperstein, F., and Yavin, E. (2003). Pro-apoptotic signaling in neuronal cells following iron and amyloid $\beta$ peptide neurotoxicity. J. Neurochem. 86, 114-125. doi: 10.1046/j.1471-4159.2003.01831.x 
LaDu, M. J. (1998). Nascent astrocyte particles differ from lipoproteins in CSF. $J$. Neurochem. 70, 2070-2081. doi: 10.1046/j.1471-4159.1998.70052070.x

Landman, N., and Kim, T. W. (2004). Got RIP? Presenilin-dependent intramembrane proteolysis in growth factor receptor signaling. Cytokine Growth Factor Rev. 15, 337-351. doi: 10.1016/j.cytogfr.2004.04.001

Lang, T., Bruns, D., Wenzel, D., Riedel, D., Holroyd, P., Thiele, C., et al. (2001). SNAREs are concentrated in cholesterol-dependent clusters that define docking and fusion sites for exocytosis. EMBO J. 20, 2202-2213. doi: 10.1093/emboj/20.9.2202

Lange, S. J., and Que, L. Jr. (1998). Oxygen activating nonheme iron enzymes. Curr. Opin. Chem. Biol. 2, 159-172. doi: 10.1016/S1367-5931(98)80057-4

Lavieu, G., Scarlatti, F., Sala, G., Carpentier, S., Levade, T., Ghidoni, R., et al. (2006), Regulation of autophagy by sphingosine kinase 1 and its role in cell survival during nutrient starvation. J. Biol. Chem. 281, 8518-8527. doi: 10.1074/jbc.M506182200

Le Gac, G., Mura, C., and Ferec, C. (2001). Complete scanning of the hereditary hemochromatosis gene (HFE) by use of denaturing HPLC. Clin. Chem. 47, 16331640.

Lebron, J. A., Bennett, M. J., Vaughn, D. E., Chirino, A. J., Snow, P. M., Mintier, G. A., et al. (1998). Crystal structure of the hemochromatosis protein HFE and characterization of its interaction with transferrin receptor. Cell 93, 111-123. doi: 10.1016/S0092-8674(00)81151-4

Lebron, J. A., West, A. G., and Bjorkman, P. J. (1999). The hemochromatosis protein HFE competes with transferrin for binding to the transferrin receptor. J. Mol. Biol. 294, 239-245. doi: 10.1006/jmbi.1999.3252

Ledeen, R. W., and Wu, G. S. (2002). Ganglioside function in calcium homeostasis and signaling. Neurochem. Res. 27, 637-647. doi: 10.1023/A:1020224016830

Ledesma, M. D. (2003). Raft disorganization leads to reduced plasmin activity in Alzheimer's disease brains. EMBO Rep. 4, 1190-1196. doi 10.1038/sj.embor.7400021

Lee, S. J., Liyanage, U., Bickel, P. E., Xia, W. M., Lansbury, P. T., and Kosik, K. S. (1998). A detergent-insoluble membrane compartment contains A $\beta$ in vivo. Nat. Med. 4, 730-734. doi: 10.1038/nm0698-730

Lee, S. Y., Patton, S. M., Henderson, R. J., and Connor, J. R. (2007). Consequences of expressing mutants of the hemochromatosis gene (HFE) into a human neuronal cell line lacking endogenous HFE. FASEB J. 21, 564-576. doi: 10.1096/fj.06$6397 \mathrm{com}$

Leoni, V., Masterman, T., Diczfalusy, U., De Luca, G., Hillert, J., and Bjorkhem, I. (2002). Changes in human plasma levels of the brain specific oxysterol 24Shydroxycholesterol during progression of multiple sclerosis. Neurosci. Lett. 331, 163-166. doi: 10.1016/S0304-3940(02)00887-X

Leoni, V., Shafaati, M., Salomon, A., Kivipelto, M., Bjorkhem, I., and Wahlund, L. O. (2006). Are the CSF levels of 24S-hydroxycholesterol a sensitive biomarker for mild cognitive impairment? Neurosci. Lett. 397, 83-87. doi: 10.1016/j.neulet.2005.11.046

Lingwood, D., Binnington, B., Rog, T., Vattulainen, I., Grzybek, M., Coskun, U., et al (2011). Cholesterol modulates glycolipid conformation and receptor activity. Nat. Chem. Biol. 7, 260-262. doi: 10.1038/nchembio.551

Liou, Y. C., Sun, A., Ryo, A., Zhou, X. Z., Yu, Z. X., Huang, H. K., et al. (2003). Role of the prolyl isomerase Pin1 in protecting against agedependent neurodegeneration. Nature 424, 556-561. doi: 10.1038/Nature 01832

Liu, G., Garrett, M. R., Men, P., Zhu, X., Perry, G., and Smith, M. A. (2005). Nanoparticle and other metal chelation therapeutics in Alzheimer disease. Biochim. Biophys. Acta 1741, 246-252. doi: 10.1016/j.bbadis.2005.06.006

Liu, G., Huang, W., Moir, R. D., Vanderburg, C. R., Lai, B., Peng, Z., et al. (2006). Metal exposure and Alzheimer's pathogenesis. J. Struct. Biol. 155, 45-51. doi: $10.1016 / j . j s b .2005 .12 .011$

Liu, X., Lv, C., Luan, X., and Lv, M. (2013). C282Y polymorphism in the HFE gene is associated with risk of breast cancer. Tumour Biol. 34, 2759-2764. doi: 10.1007/s13277-013-0833-9

Liu, Y., Lee, S. Y., Neely, E., Nandar, W., Moyo, M., Simmons, Z., et al. (2011). Mutant HFE H63D protein is associated with prolonged endoplasmic reticulum stress and increased neuronal vulnerability. J. Biol. Chem. 286, 13161-13170. doi: 10.1074/jbc.M110.170944

Lleo, A., Blesa, R., Angelopoulos, C., Pastor-Rubio, P., Villa, M., Oliva, R., et al. (2002). Transferrin C2 allele, haemochromatosis gene mutations, and risk for Alzheimer's disease. J. Neurol. Neurosurg. Psychiatry 72, 820-821. doi: $10.1136 /$ jnnp.72.6.820-a
Lloyd, R. V., Hanna, P. M., and Mason, R. P. (1997). The origin of the hydroxyl radical oxygen in the Fenton reaction. Free Radic. Biol. Med. 22, 885-888. doi: 10.1016/S0891-5849(96)00432-7

Loeffler, D. A., Connor, J. R., Juneau, P. L., Snyder, B. S., Kanaley, L., Demaggio, A. J., et al. (1995). Transferrin and iron in normal, Alzheimer's disease, and Parkinson's disease brain regions. J. Neurochem. 65, 710-724. doi: 10.1046/j.14714159.1995.65020710.x

Lopes, K. O., Sparks, D. L., and Streit, W. J. (2008). Microglial dystrophy in the aged and Alzheimer's disease brain is associated with ferritin immunoreactivity. Glia 56, 1048-1060. doi: 10.1002/Glia.20678

Lu, K. P., Hanes, S. D., and Hunter, T. (1996). A human peptidyl-prolyl isomerase essential for regulation of mitosis. Nature 380, 544-547. doi: 10.1038/380544a0

Lutjohann, D., Breuer, O., Ahlborg, G., Nennesmo, I., Siden, A., Diczfalusy, U., et al. (1996). Cholesterol homeostasis in human brain: evidence for an age-dependent flux of 24S-hydroxycholesterol from the brain into the circulation. Proc. Natl. Acad. Sci. U.S.A. 93, 9799-9804. doi: 10.1073/pnas.93.18.9799

Lutjohann, D., Papassotiropoulos, A., Bjorkhem, I., Locatelli, S., Bagli, M., Oehring, R. D., et al. (2000). Plasma 24S-hydroxycholesterol (cerebrosterol) is increased in Alzheimer and vascular demented patients. J. Lipid Res. 41, 195-198.

Mahley, R. W. (1988). Apolipoprotein E: cholesterol transport protein with expanding role in cell biology. Science 240, 622-630. doi: 10.1126/science.3283935

Mahley, R. W., Weisgraber, K. H., and Huang, Y. (2006). Apolipoprotein E4: a causative factor and therapeutic target in neuropathology, including Alzheimer's disease. Proc. Natl Acad. Sci. U.S.A. 103, 5644-5651. doi: 10.1073/pnas.0600549103

Mairuae, N., Hall Ii, E. C., Cheepsunthorn, P., Lee, S. Y., and Connor, J. R. (2010). The H63D HFE gene variant promotes activation of the intrinsic apoptotic pathway via mitochondria dysfunction following $\beta$-amyloid peptide exposure. J. Neurosci. Res. 88, 3079-3089. doi: 10.1002/jnr.22466

Mantyh, P. W., Ghilardi, J. R., Rogers, S., Demaster, E., Allen, C. J., Stimson, E. R., et al. (1993). Aluminum, iron, and zinc ions promote aggregation of physiological concentrations of $\beta$-amyloid peptide. J. Neurochem. 61, 1171-1174. doi: 10.1111/j.1471-4159.1993.tb03639.x

Mapstone, M., Cheema, A. K., Fiandaca, M. S., Zhong, X., Mhyre, T. R., Macarthur, L. H., et al. (2014). Plasma phospholipids identify antecedent memory impairment in older adults. Nat. Med. 20, 415-418. doi: 10.1038/nm.3466

Marcus, J., and Popko, B. (2002). Galactolipids are molecular determinants of myelin development and axo-glial organization. Biochim. Biophys. Acta 1573, 406-413. doi: 10.1016/S0304-4165(02)00410-5

Markesbery, W. R. (1997). Oxidative stress hypothesis in Alzheimer's disease. Free Radic. Biol. Med. 23, 134-147. doi: 10.1016/S0891-5849(96)00629-6

Marta, C. B., Taylor, C. M., Cheng, S., Quarles, R. H., Bansal, R., and Pfeiffer, S. E. (2004). Myelin associated glycoprotein cross-linking triggers its partitioning into lipid rafts, specific signaling events and cytoskeletal rearrangements in oligodendrocytes. Neuron Glia Biol. 1, 35-46. doi: 10.1017/s1740925x0 4000067

Martin, W. R., Ye, F. Q., and Allen, P. S. (1998). Increasing striatal iron content associated with normal aging. Mov. Disord. 13, 281-286. doi: 10.1002/mds.870130214

Maynard, C. J., Bush, A. I., Masters, C. L., Cappai, R., and Li, Q. X. (2005). Metals and amyloid- $\beta$ in Alzheimer's disease. Int. J. Exp. Pathol. 86, 147-159. doi: 10.1111/j.0959-9673.2005.00434.x

Mcmillan, P. N., Williams, N. I., Day, E. D., and Kaufman, B. (1972). Isolation and biochemical characterization of 3 subfractions of myelin from central nervous-tissue of adult rat. J. Neurochem. 19, 1839-1848. doi: 10.1111/j.14714159.1972.tb01472.x

Meaney, S., Hassan, M., Sakinis, A., Lutjohann, D., Von Bergmann, K., Wennmalm, A., et al. (2001). Evidence that the major oxysterols in human circulation originate from distinct pools of cholesterol: a stable isotope study. J. Lipid Res. 42, $70-78$.

Merryweather-Clarke, A. T., Pointon, J. J., Jouanolle, A. M., Rochette, J., and Robson, K. J. H. (2000). Geography of HFE C282Y and H63D mutations. Genet. Test. 4, 183-198. doi: 10.1089/10906570050114902

Michikawa, M., Fan, Q. W., Isobe, I., and Yanagisawa, K. (2000). Apolipoprotein E exhibits isoform-specific promotion of lipid efflux from astrocytes and neurons in culture. J. Neurochem. 74, 1008-1016. doi: 10.1046/j.1471-4159.2000.074 1008.x

Miller, R. H. (2002). Regulation of oligodendrocyte development in the vertebrate CNS. Prog. Neurobiol. 67, 451-467. doi: 10.1016/S0301-0082(02)00058-8 
Milton, W. J., Atlas, S. W., Lexa, F. J., Mozley, P. D., and Gur, R. E. (1991). Deep gray matter hypointensity patterns with aging in healthy adults: MR imaging at $1.5 \mathrm{~T}$. Radiology 181, 715-719.

Mitchell, R. M., Lee, S. Y., Randazzo, W. T., Simmons, Z., and Connor, J. R. (2009a). Influence of HFE variants and cellular iron on monocyte chemoattractant protein-1. J Neuroinflammation 6, 6. doi: 10.1186/1742-2094-6-6

Mitchell, R. M., Lee, S. Y., Simmons, Z., and Connor, J. R. (2009b). HFE polymorphisms affect cellular glutamate regulation. Neurobiol. Aging 32, 1114-1123. doi: 10.1016/j.neurobiolaging.2009.05.016

Mitter, D., Reisinger, C., Hinz, B., Hollmann, S., Yelamanchili, S. V., TreiberHeld, S., et al. (2003). The synaptophysin/synaptobrevin interaction critically depends on the cholesterol content. J. Neurochem. 84, 35-42. doi: 10.1046/j.14714159.2003.01258.x

Miyata, M., and Smith, J. D. (1996). Apolipoprotein E allele-specific antioxidant activity and effects on cytotoxicity by oxidative insults and $\beta$-amyloid peptides. Nat. Genet. 14, 55-61. doi: 10.1038/ng0996-55

Moalem, S., Percy, M. E., Andrews, D. F., Kruck, T. P., Wong, S., Dalton, A. J. et al. (2000). Are hereditary hemochromatosis mutations involved in Alzheimer disease? Am. J. Med. Genet. 93, 58-66. doi: 10.1002/1096-8628(20000703)93:1 $<58:$ :AID-AJMG10>3.0.CO;2-L

Mohanty, J. G., Shukla, H. D., Williamson, J. D., Launer, L. J., Saxena, S., and Rifkind, J. M. (2010). Alterations in the red blood cell membrane proteome in Alzheimer's subjects reflect disease-related changes and provide insight into altered cell morphology. Proteome Sci. 8, 11. doi: 10.1186/14775956-8-11

Molander-Melin, M., Blennow, K., Bogdanovic, N., Dellheden, B., Mansson, J. E., and Fredman, P. (2005). Structural membrane alterations in Alzheimer brains found to be associated with regional disease development; increased density of gangliosides GM1 and GM2 and loss of cholesterol in detergent-resistant membrane domains. J. Neurochem. 92, 171-182. doi: 10.1111/j.1471-4159. 2004.02849.x

Montine, T. J., Markesbery, W. R., Zackert, W., Sanchez, S. C., Roberts, L. J., and Morrow, J. D. (1999). The magnitude of brain lipid peroxidation correlates with the extent of degeneration but not with density of neuritic plaques or neurofibrillary tangles or with APOE genotype in Alzheimer's disease patients. Am. J. Pathol. 155, 863-868. doi: 10.1016/S0002-9440(10)65185-1

Morishima-Kawashima, M., and Ihara, Y. (1998). The presence of amyloid $\beta$-protein in the detergent-insoluble membrane compartment of human neuroblastoma cells. Biochemistry 37, 15247-15253. doi: 10.1021/bi981843u

Mutter, J., Naumann, J., Sadaghiani, C., Schneider, R., and Walach, H. (2004). Alzheimer disease: mercury as pathogenetic factor and apolipoprotein $\mathrm{E}$ as a moderator. Neuro Endocrinol. Lett. 25, 331-339.

Netz, D. J. A., Stith, C. M., Stumpfig, M., Kopf, G., Vogel, D., Genau, H. M., et al. (2012). Eukaryotic DNA polymerases require an iron-sulfur cluster for the formation of active complexes. Nat. Chem. Biol. 8, 125-132. doi: 10.1038/Nchembio.721

Nielsen, J. E., Jensen, L. N., and Krabbe, K. (1995). Hereditary haemochromatosis: a case of iron accumulation in the basal ganglia associated with a parkinsonian syndrome. J. Neurol. Neurosurg. Psychiatry 59, 318-321. doi: 10.1136/jnnp.59.3.318

Notkola, I. L., Sulkava, R., Pekkanen, J., Erkinjuntti, T., Ehnholm, C., Kivinen, P., et al. (1998). Serum total cholesterol, apolipoprotein E epsilon 4 allele, and Alzheimer's disease. Neuroepidemiology 17, 14-20. doi: 10.1159/000026149

Novak, A., Binnington, B., Ngan, B., Chadwick, K., Fleshner, N., and Lingwood, C. A. (2013). Cholesterol masks membrane glycosphingolipid tumor-associated antigens to reduce their immunodetection in human cancer biopsies. Glycobiology 23, 1230-1239. doi: 10.1093/glycob/cwt059

Okada, T., Wakabayashi, M., Ikeda, K., and Matsuzaki, K. (2007). Formation of toxic fibrils of Alzheimer's amyloid $\beta$-protein-(1-40) by monosialoganglioside GM1, a neuronal membrane component. J. Mol. Biol. 371, 481-489. doi: 10.1016/j.jmb.2007.05.069

Oma, S., Mawatari, S., Saito, K., Wakana, C., Tsuboi, Y., Yamada, T., et al. (2012). Changes in phospholipid composition of erythrocyte membrane in Alzheimer's disease. Dement. Geriatr. Cogn. Dis. Extra 2, 298-303. doi: 10.1159/000 341603

Ong, W. Y., and Halliwell, B. (2004). Iron, atherosclerosis, and neurodegeneration a key role for cholesterol in promoting iron-dependent oxidative damage? Ann. N. Y. Acad. Sci. 1012, 51-64. doi: 10.1196/annals.1306.005
Ong, W. Y., Tan, B., Pan, N., Jenner, A., Whiteman, M., Ong, C. N., et al. (2004) Increased iron staining in the cerebral cortex of cholesterol fed rabbits. Mech. Ageing Dev. 125, 305-313. doi: 10.1016/j.mad.2004.01.008

Osborne, N. J., Gurrin, L. C., Allen, K. J., Constantine, C. C., Delatycki, M. B., Mclaren, C. E., et al. (2010). HFE C282Y homozygotes are at increased risk of breast and colorectal cancer. Hepatology 51, 1311-1318. doi: 10.1002/Hep.23448

Panzenboeck, U., Balazs, Z., Sovic, A., Hrzenjak, A., Levak-Frank, S., Wintersperger, A., et al. (2002). ABCAl and scavenger receptor class B, type I, are modulators of reverse sterol transport at an in vitro blood-brain barrier constituted of porcine brain capillary endothelial cells. J. Biol. Chem. 277, 42781-42789. doi: 10.1074/jbc.M207601200

Papassotiropoulos, A., Lutjohann, D., Bagli, M., Locatelli, S., Jessen, F., Buschfort, R., et al. (2002). 24S-hydroxycholesterol in cerebrospinal fluid is elevated in early stages of dementia. J. Psychiatr. Res. 36, 27-32. doi: 10.1016/S00223956(01)00050-4

Percy, M., Moalem, S., Garcia, A., Somerville, M. J., Hicks, M., Andrews, D., et al. (2008). Involvement of ApoE E4 and H63D in sporadic Alzheimer's disease in a folate-supplemented Ontario population. J. Alzheimers Dis. 14, 69-84.

Perez, G. I., Jurisicova, A., Matikainen, T., Moriyama, T., Kim, M. R., Takai, Y., et al. (2005). A central role for ceramide in the age-related acceleration of apoptosis in the female germline. FASEB J. 19, 860-862. doi: 10.1096/fj.04-2903fje

Petro, K. A., and Schengrund, C. (2007). Disruption of lipid rafts affects ganglioside composition and distribution in N2a cells. J. Neurochem. 102, 234-234.

Pettegrew, J. W., Panchalingam, K., Hamilton, R. L., and Mcclure, R. J. (2001). Brain membrane phospholipid alterations in Alzheimer's disease. Neurochem. Res. 26, 771-782. doi: 10.1023/A:1011603916962

Pfrieger, F. W. (2003a). Outsourcing in the brain: do neurons depend on cholesterol delivery by astrocytes? Bioessays 25, 72-78. doi: 10.1002/Bies. 10195

Pfrieger, F. W. (2003b). Role of cholesterol in synapse formation and function. Biochim. Biophys. Acta 1610, 271-280. doi: 10.1016/S0005-2736(03)00024-5

Pitas, R. E., Boyles, J. K., Lee, S. H., Foss, D., and Mahley, R. W. (1987a). Astrocytes synthesize apolipoprotein E and metabolize apolipoprotein E-containing lipoproteins. Biochim. Biophys. Acta 917, 148-161. doi: 10.1016/0005-2760(87)90295-5

Pitas, R. E., Boyles, J. K., Lee, S. H., Hui, D., and Weisgraber, K. H. (1987b). Lipoproteins and their receptors in the central nervous system. Characterization of the lipoproteins in cerebrospinal fluid and identification of apolipoprotein B,E(LDL) receptors in the brain. J. Biol. Chem. 262, 14352-14360.

Plotz, E. J., Kabara, J. J., Davis, M. E., Leroy, G. V., and Gould, R. G. (1968). Studies on the synthesis of cholesterol in the brain of the human fetus. Am. J. Obstet. Gynecol. 101, 534-538.

Powers, K. M., Smith-Weller, T., Franklin, G. M., Longstreth, W. T., Swanson, P. D., and Checkoway, H. (2009). Dietary fats, cholesterol and iron as risk factors for Parkinson's disease. Parkinsonism Relat. Disord. 15, 47-52. doi: 10.1016/j.parkreldis.2008.03.002

Pratico, D., Clark, C. M., Liun, F., Lee, V. Y. M., and Trojanowski, J. Q. (2002). Increase of brain oxidative stress in mild cognitive impairment a possible predictor of Alzheimer disease. Arch. Neurol. 59, 972-976. doi: 10.1001/archneur.59.6.972

Pulliam, J. F., Jennings, C. D., Kryscio, R. J., Davis, D. G., Wilson, D., Montine, T. J., et al. (2003). Association of HFE mutations with neurodegeneration and oxidative stress in Alzheimer's disease and correlation with APOE. Am. J. Med. Genet. B Neuropsychiatr. Genet. 119B, 48-53. doi: 10.1002/ajmg.b.10069

Rapp, A., Gmeiner, B., and Huttinger, M. (2006). Implication of apoE isoforms in cholesterol metabolism by primary rat hippocampal neurons and astrocytes. Biochimie 88, 473-483. doi: 10.1016/j.biochi.2005.10.007

Roberts, B. R., Ryan, T. M., Bush, A. I., Masters, C. L., and Duce, J. A. (2012). The role of metallobiology and amyloid- $\beta$ peptides in Alzheimer's disease. J. Neurochem. 120(Suppl. 1), 149-166. doi: 10.1111/j.1471-4159.2011.07500.x

Rogers, J. T., and Lahiri, D. K. (2004). Metal and inflammatory targets for Alzheimer's disease. Curr. Drug Targets 5, 535-551. doi: 10.2174/13894500433 45272

Rogers, J. T., Randall, J. D., Cahill, C. M., Eder, P. S., Huang, X. D., Gunshin, H., et al. (2002). An iron-responsive element type II in the $5^{\prime}$-untranslated region of the Alzheimer's amyloid precursor protein transcript. J. Biol. Chem. 277, 4551845528. doi: 10.1074/jbc.M207435200

Roher, A. E., Kuo, Y. M., Kokjohn, K. M., Emmerling, M. R., and Gracon, S. (1999). Amyloid and lipids in the pathology of Alzheimer disease. Amyloid 6, 136-145. doi: $10.3109 / 13506129909007315$ 
Rollins, B. J. (1997). Chemokines. Blood 90, 909-928.

Rotig, A., Delonlay, P., Chretien, D., Foury, F., Koenig, M., Sidi, D., et al. (1997). Aconitase and mitochondrial iron-sulphur protein deficiency in Friedreich ataxia. Nat. Genet. 17, 215-217. doi: 10.1038/ng1097-215

Rottkamp, C. A., Raina, A. K., Zhu, X., Gaier, E., Bush, A. I., Atwood, C. S., et al. (2001). Redox-active iron mediates amyloid- $\beta$ toxicity. Free Radic. Biol. Med. 30 447-450. doi: 10.1016/S0891-5849(00)00494-9

Rouault, T. A., and Tong, W. H. (2005). Iron-sulphur cluster biogenesis and mitochondrial iron homeostasis. Nat. Rev. Mol. Cell Biol. 6, 345-351. doi: $10.1038 / \mathrm{Nrm} 1620$

Ryland, L. K., Fox, T. E., Liu, X., Loughran, T. P., and Kester, M. (2011). Dysregulation of sphingolipid metabolism in cancer. Cancer Biol. Ther. 11, 138-149. doi: 10.4161/cbt.11.2.14624

Ryo, A., Nakamura, M., Wulf, G., Liou, Y. C., and Lu, K. P. (2001). Pin 1 regulates turnover and subcellular localization of $\beta$-catenin by inhibiting its interaction with APC. Nat. Cell Biol. 3, 793-801. doi: 10.1038/ncb0901-793

Sabolovic, D., Roudier, M., Boynard, M., Pautou, C., Sestier, C., Fertil, B., et al (1997). Membrane modifications of red blood cells in Alzheimer's disease. $J$. Gerontol. A Biol. Sci. Med. Sci. 52, B217-B220. doi: 10.1093/gerona/52A.4.B217

Saher, G., Brugger, B., Lappe-Siefke, C., Mobius, W., Tozawa, R., Wehr, M. C., et al. (2005). High cholesterol level is essential for myelin membrane growth. Nat. Neurosci. 8, 468-475. doi: 10.1038/nn1426

Saito, M., Benson, E. P., Saito, M., and Rosenberg, A. (1987). Metabolism of cholesterol and triacylglycerol in cultured chick neuronal cells, glial-cells, and fibroblasts - accumulation of esterified cholesterol in serum-free culture. $J$. Neurosci. Res. 18, 319-325. doi: 10.1002/jnr.490180208

Salter-Cid, L., Brunmark, A., Peterson, P. A., and Yang, Y. (2000). The major histocompatibility complex-encoded class I-like HFE abrogates endocytosis of transferrin receptor by inducing receptor phosphorylation. Genes Immun. 1, 409-417. doi: 10.1038/sj.gene.6363697

Sampietro, M., Caputo, L., Casatta, A., Meregalli, M., Pellagatti, A., Tagliabue, J., etal. (2001). The hemochromatosis gene affects the age of onset of sporadic Alzheimer's disease. Neurobiol. Aging 22, 563-568. doi: 10.1016/S01974580(01)00219-6

Satoi, H., Tomimoto, H., Ohtani, R., Kitano, T., Kondo, T., Watanabe M., et al. (2005). Astroglial expression of ceramide in Alzheimer's disease brains: A role during neuronal apoptosis. Neuroscience 130, 657-666. doi 10.1016/j.neuroscience.2004.08.056

Sayre, L. M., Perry, G., Atwood, C. S., and Smith, M. A. (2000). The role of metals in neurodegenerative diseases. Cell. Mol. Biol. (Noisy-le-grand) 46, 731-741.

Schengrund, C. L. (2010). Lipid rafts: keys to neurodegeneration. Brain Res. Bull. 82, 7-17. doi: 10.1016/j.brainresbull.2010.02.013

Schengrund, C. L., Ali-Rahmani, F., and Ramer, J. C. (2012). Cholesterol, GM1, and autism. Neurochem. Res. 37, 1201-1207. doi: 10.1007/s11064-011-0697-6

Schmechel, D. E. (1993). Increased amyloid $\beta$-peptide deposition in cerebral cortex as a consequence of apolipoprotein $\mathrm{E}$ genotype in late-onset Alzheimer disease Proc. Natl Acad. Sci. U.S.A. 90, 9649-9653. doi: 10.1073/pnas.90.20.9649

Schreurs, B. G. (2010). The effects of cholesterol on learning and memory. Neurosci. Biobehav. Rev. 34, 1366-1379. doi: 10.1016/j.neubiorev.2010.04.010

Schubert, D., and Chevion, M. (1995). The role of iron in $\beta$-amyloid toxicity. Biochem. Biophys. Res. Commun. 216, 702-707. doi: 10.1006/bbrc.1995.2678

Shaheen, N. J., Silverman, L. M., Keku, T., Lawrence, L. B., Rohlfs, E. M., Martin, C. F., et al. (2003). Association between hemochromatosis (HFE) gene mutation carrier status and the risk of colon cancer. J. Natl. Cancer Inst. 95, 154-159. doi: 10.1093/jnci/95.2.154

Shobab, L. A., Hsiung, G. Y. R., and Feldman, H. H. (2005). Cholesterol in Alzheimer's disease. Lancet Neurol. 4, 841-852. doi: 10.1016/S14744422(05)70248-9

Simon, M., Bourel, M., Fauchet, R., and Genetet, B. (1976). Association of HLA-A3 and HLA-B14 antigens with idiopathic haemochromatosis. Gut 17, 332-334. doi: 10.1136/gut.17.5.332

Simpson, M. A., Cross, H., Proukakis, C., Priestman, D. A., Neville, D. C. A., Reinkensmeier, G., et al. (2004). Infantile-onset symptomatic epilepsy syndrome caused by a homozygous loss-of-function mutation of GM3 synthase. Nat. Genet 36, 1225-1229. doi: 10.1038/Ng1460

Sjogren, M., Mielke, M., Gustafson, D., Zandi, P., and Skoog, I. (2006). Cholesterol and Alzheimer's disease - is there a relation? Mech. Ageing Dev. 127, 138-147. doi 10.1016/j.mad.2005.09.020
Skinner, E. R., Watt, C., Besson, J. A. O., and Best, P. V. (1989). Lipid-composition of different regions of the brain in patients with Alzheimers-disease. Biochem. Soc. Trans. 17, 213-214.

Smith, M. A. (2006). Oxidative stress and iron imbalance in Alzheimer disease: how rust became the fuss! J. Alzheimers Dis. 9, 305-308.

Smith, M. A., Wehr, K., Harris, P. L. R., Siedlak, S. L., Connor, J. R., and Perry, G. (1998). Abnormal localization of iron regulatory protein in Alzheimer's disease. Brain Res. 788, 232-236. doi: 10.1016/S0006-8993(98)00002-X

Snider, A. J., Gandy, K. A. O., and Obeid, L. M. (2010). Sphingosine kinase: role in regulation of bioactive sphingolipid mediators in inflammation. Biochimie 92, 707-715. doi: 10.1016/j.biochi.2010.02.008

Soderberg, M., Edlund, C., Alafuzoff, I., Kristensson, K., and Dallner, G. (1992). Lipid-Composition in different regions of the brain in Alzheimers-disease senile dementia of Alzheimers type. J. Neurochem. 59, 1646-1653. doi: 10.1111/j.14714159.1992.tb10994.x

Sparks, D. L., Lemieux, S. K., Haut, M. W., Baxter, L. C., Johnson, S. C., Sparks, L. M. et al. (2008). Hippocampal volume change in the Alzheimer disease CholesterolLowering Treatment trial. Cleve. Clin. J. Med. 75(Suppl. 2), S87-S93. doi: 10.3949/ccjm.75.Suppl_2.S87

Spiegel, S., and Milstien, S. (2002). Sphingosine 1-phosphate, a key cell signaling molecule. J. Biol. Chem. 277, 25851-25854. doi: 10.1074/jbc.R200007200

Srivastava, R. A., Srivastava, N., Averna, M., Lin, R. C., Korach, K. S., Lubahn, D. B., et al. (1997). Estrogen up-regulates apolipoprotein E (ApoE) gene expression by increasing ApoE mRNA in the translating pool via the estrogen receptor $\alpha$-mediated pathway. J. Biol. Chem. 272, 33360-33366. doi: $10.1074 / j b c .272 .52 .33360$

Stetzkowski-Marden, F., Recouvreur, M., Camus, G., Cartaud, A., Marchand, S., and Cartaud, J. (2006). Rafts are required for acetylcholine receptor clustering. J. Mol. Neurosci. 30, 37-38. doi: 10.1385/JMN:30:1:37

Stone, D. J., Rozovsky, I., Morgan, T. E., Anderson, C. P., Haiian, H., and Finch, C. E. (1997). Astrocytes and microglia respond to estrogen with increased apoE mRNA in vivo and in vitro. Exp. Neurol. 143, 313-318. doi: 10.1006/exnr.1996.6360

Suzuki, S., Kiyosue, K., Hazama, S., Ogura, A., Kashihara, M., Hara, T., et al. (2007). Brain-derived neurotrophic factor regulates cholesterol metabolism for synapse development. J. Neurosci. 27, 6417-6427. doi: 10.1523/JNEUROSCI.069007.2007

Suzuki, S., Numakawa, T., Shimazu, K., Koshimizu, H., Hara, T., Hatanaka, H., et al. (2004). BDNF-induced recruitment of TrkB receptor into neuronal lipid rafts: roles in synaptic modulation. J. Cell Biol. 167, 1205-1215. doi: $10.1083 /$ jcb.200404106

Svennerholm, L., and Gottfries, C. G. (1994). Membrane-lipids, selectively diminished in Alzheimer brains, suggest synapse loss as a primary event in early-onset form (type-I) and demyelination in late-onset form (type-Ii). J. Neurochem. 62, 1039-1047. doi: 10.1046/j.1471-4159.1994.62031039.x

Syrjakoski, K., Fredriksson, H., Ikonen, T., Kuukasjarvi, T., Autio, V., Matikainen, M. P., et al. (2006). Hemochromatosis gene mutations among Finnish male breast and prostate cancer patients. Int. J. Cancer 118, 518-520. doi: 10.1002/Ijc. 21331

Takamori, S., Holt, M., Stenius, K., Lemke, E. A., Gronborg, M., Riedel, D., et al. (2006). Molecular anatomy of a trafficking organelle. Cell 127, 831-846. doi: 10.1016/j.cell.2006.10.030

Thiele, C., Hannah, M. J., Fahrenholz, F., and Huttner, W. B. (2000). Cholesterol binds to synaptophysin and is required for biogenesis of synaptic vesicles. Nat. Cell Biol. 2, 42-49. doi: 10.1038/71366

Todorich, B. M., and Connor, J. R. (2004). Redox metals in Alzheimer's disease. Ann. N. Y. Acad. Sci. 1012, 171-178. doi: 10.1196/annals.1306.014

Tong, W. H., and Rouault, T. A. (2006). Functions of mitochondrial ISCU and cytosolic ISCU in mammalian iron-sulfur cluster biogenesis and iron homeostasis. Cell Metab. 3, 199-210. doi: 10.1016/j.cmet.2006.02.003

Tsui-Pierchala, B. A., Encinas, M., Milbrandt, J., and Johnson, E. M. (2002). Lipid rafts in neuronal signaling and function. Trends Neurosci. 25, 412-417. doi: 10.1016/S0166-2236(02)02215-4

Turbino-Ribeiro, S. M. L., Silva, M. E., Chianca, D. A., De Paula, H., Cardoso, L. M., Colombari, E., et al. (2003). Iron overload in hypercholesterolemic rats affects iron homeostasis and serum lipids but not blood pressure. J. Nutr. 133, 15-20.

Valenza, M., Rigamonti, D., Goffredo, D., Zuccato, C., Fenu, S., Jamot, L., et al. (2005). Dysfunction of the cholesterol biosynthetic pathway in Huntington's disease. J. Neurosci. 25, 9932-9939. doi: 10.1523/JNEUROSCI.3355-05.2005 
Vance, J. E. (2006). Lipid imbalance in the neurological disorder, Niemann-Pick C disease. FEBS Lett. 580, 5518-5524. doi: 10.1016/j.febslet.2006.06.008

Vaya, J., and Schipper, H. M. (2007). Oxysterols, cholesterol homeostasis, and Alzheimer disease. J. Neurochem. 102, 1727-1737. doi: 10.1111/j.1471-4159.2007. 04689.x

Veatch, S. L., and Keller, S. L. (2005). Seeing spots: complex phase behavior in simple membranes. Biochim. Biophys. Acta 1746, 172-185. doi: 10.1016/j.bbamcr. 2005.06.010

Venable, M. E., Lee, J. Y., Smyth, M. J., Bielawska, A., and Obeid, L. M. (1995). Role of ceramide in cellular senescence. J. Biol. Chem. 270, 30701-30708. doi: 10.1074/jbc.270.51.30701

Vetrivel, K. S., Cheng, H. P., Kim, S. H., Chen, Y., Barnes, N. Y., Parent, A. T., et al. (2005). Spatial segregation of $\gamma$-secretase and substrates in distinct membrane domains. J. Biol. Chem. 280, 25892-25900. doi: 10.1074/jbc.M503570200

Vrotsos, E. G., Kolattukudy, P. E., and Sugaya, K. (2009). MCP-1 involvement in glial differentiation of neuroprogenitor cells through APP signaling. Brain Res. Bull. 79, 97-103. doi: 10.1016/j.brainresbull.2009.01.004

Waelsch, H., Sperry, W. M., and Stoyanoff, V. A. (1940). A study of the synthesis and deposition of lipids in brain and other tissues with deuterium as an indicator. $J$. Biol. Chem. 135, 291-296.

Waheed, A., Grubb, J. H., Zhou, X. Y., Tomatsu, S., Fleming, R. E., Costaldi, M. E., et al. (2002). Regulation of transferrin-mediated iron uptake by HFE, the protein defective in hereditary hemochromatosis. Proc. Natl. Acad. Sci. U.S.A. 99, 3117-3122. doi: 10.1073/pnas.042701499

Waheed, A., Parkkila, S., Saarnio, J., Fleming, R. E., Zhou, X. Y., Tomatsu, S., et al (1999). Association of HFE protein with transferrin receptor in crypt enterocytes of human duodenum. Proc. Natl. Acad. Sci. U.S.A. 96, 1579-1584. doi: 10.1073/pnas.96.4.1579

Waheed, A., Parkkila, S., Zhou, X. Y., Tomatsu, S., Tsuchihashi, Z., Feder, J. N., et al. (1997). Hereditary hemochromatosis: Effects of C282Y and H63D mutations on association with $\beta_{2}$-microglobulin, intracellular processing, and cell surface expression of the HFE protein in COS-7 cells. Proc. Natl. Acad. Sci. U.S.A. 94, 12384-12389. doi: 10.1073/pnas.94.23.12384

Wang, X. S., Lee, S., Simmons, Z., Boyer, P., Scott, K., Liu, W., et al. (2004). Increased incidence of the Hfe mutation in amyotrophic lateral sclerosis and related cellular consequences. J. Neurol. Sci. 227, 27-33. doi: 10.1016/j.jns.2004.08.003

Wellington, C. L. (2004). Cholesterol at the crossroads: Alzheimer's disease and lipid metabolism. Clin. Genet. 66, 1-16. doi: 10.1111/j.1399-0004.2004.00280.x

Willmann, R., Pun, S., Stallmach, L., Sadasivam, G., Santos, A. F., Caroni, P., et al. (2006). Cholesterol and lipid microdomains stabilize the postsynapse at the neuromuscular junction. EMBO J. 25, 4050-4060. doi: 10.1038/sj.emboj. 7601288

Wolozin, B. (2003). Cyp46 (24S-cholesterol hydroxylase): a genetic risk factor for Alzheimer disease. Arch. Neurol. 60, 16-18. doi: 10.1001/archneur.60.1.16

Wolozin, B. (2004). Cholesterol, statins and dementia. Curr. Opin. Lipidol. 15, 667-672. doi: 10.1097/00041433-200412000-00007

Wu, G. S., Lu, Z. H., Obukhov, A. G., Nowycky, M. C., and Ledeen, R. W. (2007). Induction of calcium influx through TRPC 5 channels by cross-linking of GM1 ganglioside associated with $\alpha 5 \beta 1$ integrin initiates neurite outgrowth. J. Neurosci. 27, 7447-7458. doi: 10.1523/Jneurosci.4266-06.2007
Wulf, G., Finn, G., Suizu, F., and Lu, K. P. (2005). Phosphorylation-specific prolyl isomerization: is there an underlying theme? Nat. Cell Biol. 7, 435-441. doi: $10.1038 /$ Ncb0505-435

Wulf, G. M., Ryo, A., Wulf, G. G., Lee, S. W., Niu, T. H., Petkova, V., et al. (2001). Pin1 is overexpressed in breast cancer and cooperates with Ras signaling in increasing the transcriptional activity of c-Jun towards cyclin D1. EMBO J. 20, 3459-3472. doi: 10.1093/emboj/20.13.3459

Yamamoto, N., Fukata, Y., Fukata, M., and Yanagisawa, K. (2007). GM1-gangliosideinduced $\mathrm{A} \beta$ assembly on synaptic membranes of cultured neurons. Biochim. Biophys. Acta 1768, 1128-1137. doi: 10.1016/j.bbamem.2007.01.009

Yanagisawa, K. (2005). GM1 ganglioside and the seeding of amyloid in Alzheimer's disease: endogenous seed for Alzheimer amyloid. Neuroscientist 11, 250-260. doi: $10.1177 / 1073858405275177$

Zerbinatti, C. V., and Bu, G. (2005). LRP and Alzheimer's disease. Rev. Neurosci. 16, 123-135. doi: 10.1515/REVNEURO.2005.16.2.123

Zha, Q., Ruan, Y., Hartmann, T., Beyreuther, K., and Zhang, D. (2004). GM1 ganglioside regulates the proteolysis of amyloid precursor protein. Mol. Psychiatry 9, 946-952. doi: 10.1038/sj.mp.4001509

Zhang, X., Surguladze, N., Slagle-Webb, B., Cozzi, A., and Connor, J. R. (2007). Cellular iron status influences the functional relationship between microglia and oligodendrocytes. Am. J. Hematol. 82, 573-573.

Zhou, L. M., Azfer, A., Niu, J. L., Graham, S., Choudhury, M., Adamski, F. M., et al. (2006). Monocyte chemoattractant protein-1 induces a novel transcription factor that causes cardiac myocyte apoptosis and ventricular dysfunction. Circ. Res. 98, 1177-1185. doi: 10.1161/01.Res.0000220106.64661.71

Zhu, W. Z., Zhong, W. D., Wang, W., Zhan, C. J., Wang, C. Y., and Qi, J. P. (2009). Quantitative MR phase-corrected imaging to investigate increased brain iron deposition of patients with Alzheimer disease. Radiology 253, 497-504. doi: 10.1148/radiol.2532082324

Zinser, E. G., Hartmann, T., and Grimm, M. O. W. (2007). Amyloid $\beta$ protein and lipid metabolism. Biochim. Biophys. Acta 1768, 1991-2001. doi: 10.1016/j.bbamem.2007.02.014

Conflict of Interest Statement: The authors declare that the research was conducted in the absence of any commercial or financial relationships that could be construed as a potential conflict of interest.

Received: 21 April 2014; paper pending published: 09 June 2014; accepted: 24 June 2014; published online: 08 July 2014.

Citation: Ali-Rahmani F, Schengrund C-L and Connor JR (2014) HFE gene variants, iron, and lipids: a novel connection in Alzheimer's disease. Front. Pharmacol. 5:165. doi: 10.3389/fphar.2014.00165

This article was submitted to Drug Metabolism and Transport, a section of the journal Frontiers in Pharmacology.

Copyright (C) 2014 Ali-Rahmani, Schengrund and Connor. This is an open-access article distributed under the terms of the Creative Commons Attribution License (CC BY). The use, distribution or reproduction in other forums is permitted, provided the original author(s) or licensor are credited and that the original publication in this journal is cited, in accordance with accepted academic practice. No use, distribution or reproduction is permitted which does not comply with these terms. 